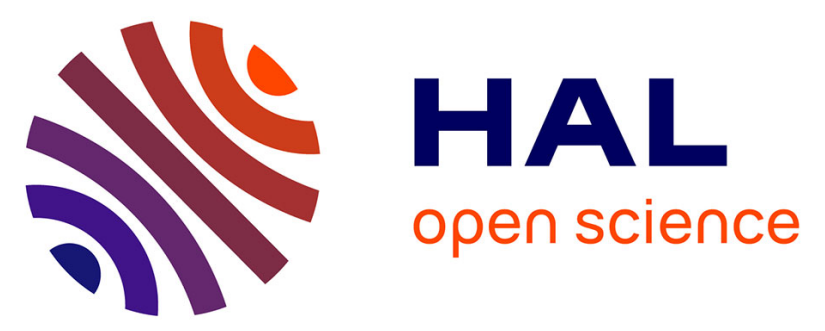

\title{
Detection of glyceraldehyde and glycerol in VUV processed interstellar ice analogues containing formaldehyde: a general formation route for sugars and polyols
}

\author{
Y Layssac, A. Gutiérrez-Quintanilla, T. Chiavassa, Fabrice Duvernay
}

\section{To cite this version:}

Y Layssac, A. Gutiérrez-Quintanilla, T. Chiavassa, Fabrice Duvernay. Detection of glyceraldehyde and glycerol in VUV processed interstellar ice analogues containing formaldehyde: a general formation route for sugars and polyols. Monthly Notices of the Royal Astronomical Society, 2020, 496 (4), pp.2592-5307. 10.1093/mnras/staa1875 . hal-02883737

\section{HAL Id: hal-02883737 \\ https://hal-amu.archives-ouvertes.fr/hal-02883737}

Submitted on 29 Jun 2020

HAL is a multi-disciplinary open access archive for the deposit and dissemination of scientific research documents, whether they are published or not. The documents may come from teaching and research institutions in France or abroad, or from public or private research centers.
L'archive ouverte pluridisciplinaire HAL, est destinée au dépôt et à la diffusion de documents scientifiques de niveau recherche, publiés ou non, émanant des établissements d'enseignement et de recherche français ou étrangers, des laboratoires publics ou privés. 


\title{
Detection of glyceraldehyde and glycerol in VUV processed interstellar ice analogues containing formaldehyde: a general formation route for sugars and polyols
}

\author{
Y. Layssac, ${ }^{1}{ }^{\star}$ A. Gutiérrez-Quintanilla, ${ }^{1}$ T. Chiavassa ${ }^{1}$ and F. Duvernay ${ }^{1} \dagger$ \\ ${ }^{1}$ Aix-Marseille Université, Laboratoire PIIM, Team ASTRO, Service 252, Saint Jérôme, \\ Ave. Escadrille Normandie Niemen, 13013 Marseille,Franc
}

\begin{abstract}
Complex organic molecules (COMs) have been identified toward high -and low- mass protostars as well as molecular clouds. Among them sugar-like and polyol two carbon-bearing molecules such as glycolaldehyde and ethylene glycol are of special interest. Recent laboratory experiments have shown that they can efficiently be formed via atom addition reactions between accreting $\mathrm{H}$-atoms and $\mathrm{CO}$ molecules or via energetic processes (UV, electrons) on ice analogues containing methanol or formaldehyde. In this study we report new laboratory experiments on the low temperature solid state formation of complex organic molecules -the first sugar glyceraldehyde and its saturated derivative glycerol- through VUV photolysis performed at three different temperatures $(15,50$ and $90 \mathrm{~K})$ of astrochemically relevant ices composed of water and formaldehyde. We get evidence that the species production depends on the ice temperature during photolysis. The results presented here indicate that a general scheme of aldose and polyol formation is plausible and that heavier COMs than GA and EG could exist in interstellar environments. We propose a general pathway involving radical-formaldehyde reactions as common initiation step for aldose and polyol formation. Future telescope observations may give additional clues on their presence in star forming regions as observations are currently limited because of the detection thresholds.
\end{abstract}

Key words: Astrochemistry - methods: laboratory: solid state - techniques: spectroscopic ISM: evolution

\section{INTRODUCTION}

To date, more than 200 molecules ranging from molecular hydrogen up to fullerenes have been detected in circumstellar and interstellar environments. About sixty of them are the so called complex organic molecules (hereafter COMs) usually defined by the astronomical community as carbon-bearing organics comprised of six or more atoms. They have been unambiguously identified in a large variety of objects and environments: in dark clouds and pre-stellar cores (Marcelino et al. 2007; Öberg et al. 2010; Bacmann et al. 2012; Cernicharo et al. 2012; Vastel et al. 2014; Jiménez-Serra et al. 2016), in photon-dominated regions (Guzmán et al. 2014), in hot cores and giant molecular clouds (Hollis et al. 2000; Martín-Pintado et al. 2001; Requena-Torres et al. 2008; Belloche et al. 2013), in low and high mass protostar environments (Blake et al. 1987; Caselli \& Ceccarelli 2012; Neill et al. 2014; Tercero et al. 2015; Coutens et al. 2015; Taquet et al. 2015; Jørgensen et al. 2016; Rivilla et al. 2016), as well as in molecular outflows (Arce et al. 2008; Codella

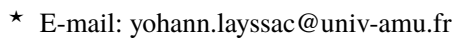

$\dagger$ E-mail: fabrice.duvernay@univ-amu.fr
}

et al. 2015). Among these COMs, a special interest is given to glycolaldehyde (hereafter GA) and ethylene glycol (hereafter EG) the simplest polyol, which are among the largest detected COMs in the ISM.

GA and EG were observed in the IRAS 16293-2422 (Jørgensen et al. 2012) and NGC 1333-IRAS2A protostars (Coutens et al. 2015) for example. They were also detected in our Solar System, in the 67P comet (Goesmann et al. 2015; Meringer et al. 2018). It is thought that GA and EG are perfect precursors for the formation of glyceraldehyde (GCA) - the first sugar - and its saturated polyol derivative, glycerol (GCO) (Zhu et al. 2020; Kaiser et al. 2015; Fedoseev et al. 2017). Although they have not yet been observed in the ISM, clues of their presence have been found in meteorites. Indeed, a rich spectrum of polyols, including glycerol have been detected in carbonaceous chondrites (Cooper et al. 2001; Cooper \& Rios 2016). Considering that cometary material may have an interstellar origin, this makes glycerol and glyceraldehyde species of astrochemical interest.

Additionally to observational studies, laboratory experiments on interstellar ice analogues submitted to UV light, H-atom flux and ionizing radiations have been performed in order to understand 


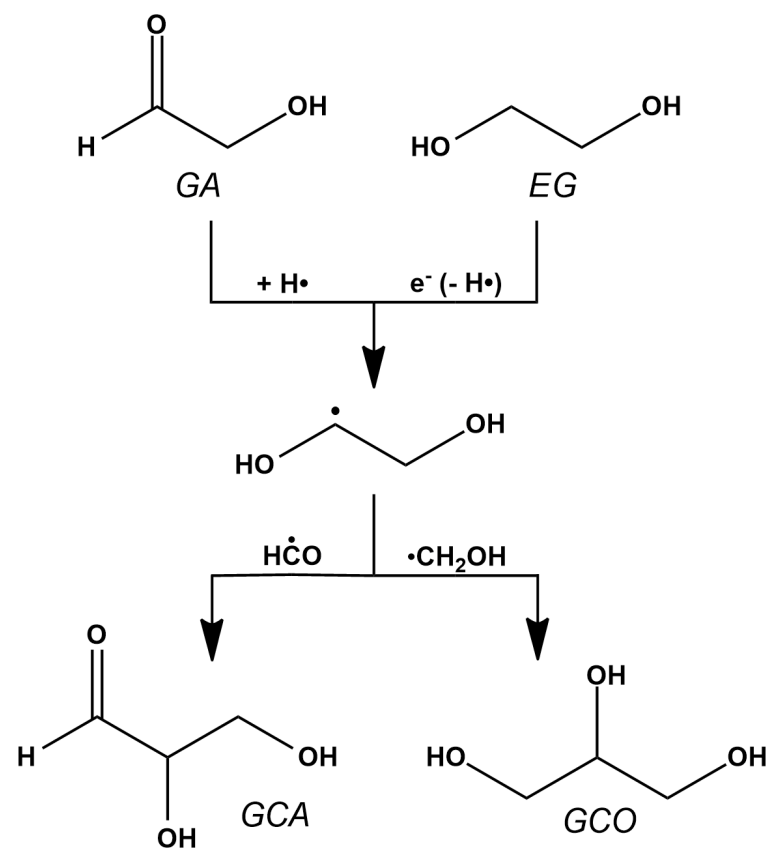

Figure 1. GCA and GCO formation pathways adapted from (Fedoseev et al. 2017) (formation of GCA and GCO from GA hydrogenation) and (Kaiser et al. 2015) and (Zhu et al. 2020) (formation of GCO from EG and energetic electrons).

COM formation such as glycolaldehyde, sugars and polyols under astrophysical conditions (Zhu et al. 2020; Kaiser et al. 2015; Fedoseev et al. 2017).

Recent laboratory experiments demonstrate that complex molecules such as GA, EG and GCO are efficiently formed via $\mathrm{H}$-atom addition on interstellar ice analogues containing $\mathrm{CO}$ and CO:GA (Fedoseev et al. 2017; Chuang et al. 2016). The proposed formation pathway passes through radical-radical recombinations which produce successfully, from GA, both the GCA and GCO molecules (Fig. 1, left side, adapted from Fedoseev et al. (2017)). In this mechanism, GA is necessary to produce the two carbon bearing radical by $\mathrm{H}$ addition at $13 \mathrm{~K}$. Then, the three carbon bearing molecules (hereafter $\mathrm{C}_{3} \mathrm{COMs}$ ) -GCO and GCA- can be obtained by recombination with $\mathrm{HCO}$ and $\mathrm{CH}_{2} \mathrm{OH}$ respectively.

Polyols such as EG and GCO can also be formed from pure methanol ices exposed to ionizing radiation (Kaiser et al. 2015; Zhu et al. 2020). COMs including polyols were analysed by PI-ReToF (Kaiser et al. 2015) and by two-dimensional gas chromatography coupled to time-of-flight mass spectrometry (GC X GC-TOFMS, Zhu et al. (2020)). The authors of these studies proposed a formation mechanism based on $\mathrm{H}$-atom abstraction and radical-radical recombination (Fig. 1, right side, adapted from Kaiser et al. (2015) and Zhu et al. (2020)). In this mechanism, EG (previously formed from the recombination of two $\mathrm{CH}_{2} \mathrm{OH}$ radicals) is necessary to produce the two carbon bearing radical by $\mathrm{H}$-abstraction which is able to give GCO by direct barrierless recombination with another $\mathrm{CH}_{2} \mathrm{OH}$ radical Kaiser et al. (2015); Zhu et al. (2020).

In this paper, new experimental results about GCA and GCO formation in astrochemically relevant conditions are presented. We focus on formaldehyde as precursor for GCA and GCO formation as it is a simple and abundant molecule in interstellar ices (Chiar et al. 2000; Gibb et al. 2004; Boogert et al. 2008) and because it has an excellent efficiency in producing GA and EG (Bennett \& Kaiser
2007; Fedoseev et al. 2015; Butscher et al. 2015, 2016; Chuang et al. 2016) which are supposed to be good precursors for GCA and GCO formation. In addition, it is the key molecule in the formose reaction which is known to produce a great diversity of sugar (Zweckmair et al. 2014). Even if in the case of interstellar conditions, this reaction is unlikely, it seems that formaldehyde is able to produce sugars in these conditions in a selective way (Meinert et al. 2016). We want to investigate in more details the chemistry that formaldehyde can offer in the interstellar medium, trying to draw a general formoselike reaction scheme for sugar and related compound formation in such environments. For the time being, astronomical observations of sugar-like species and polyols are limited to the detection of two carbons bearing molecules, we are therefore trying to push further the study of formaldehyde chemistry in order to foresee what level of complexity can be achieved in the ISM.

In Butscher et al. (2016), we already showed that EG and GA are efficiently formed from the $13 \mathrm{~K}$ VUV photolysis of $\mathrm{H}_{2} \mathrm{O} / \mathrm{H}_{2} \mathrm{CO}$ ices whereas in pure formaldehyde ices polyoxomethylene (POM, the formaldehyde polymer) is efficiently produced. In this contribution, we get new results with $15 \mathrm{~K}$ VUV photolysis conditions and we also perform irradiations at higher temperatures (50 and $90 \mathrm{~K}$ ) to obtain clues on reaction mechanisms. Significant changes regarding the newly formed species as well as their relative abundances are observed. After an experimental part (section 2), we describe our infrared and mass spectrometry results and we compare them to each other in a discussion section where formation mechanisms are also discussed. Astrophysical implications are considered before conclusion.

\section{EXPERIMENTAL}

Formaldehyde ${ }^{12} \mathrm{C}$ and ${ }^{13} \mathrm{C}$ were purchased as a polymer (paraformaldehyde) from Sigma Aldrich (99\% purity) and heated under vacuum up to $90{ }^{\circ} \mathrm{C}$ to produce the gas-phase monomer. Glycolaldehyde (GA) was purchased as a dimer from Sigma Aldrich (99.95\% purity) and was heated under vacuum up to $80^{\circ} \mathrm{C}$ to obtain the gas-phase monomer. Water, ethylene glycol (EG) and methanol (Aldrich, all three $\geq 99.9 \%$ purity) were doubly distilled under vacuum before injection. Glyceraldehyde (GCA) and glycerol (GCO) were purchased from Sigma Aldrich (90 and 99\% purity respectively). Gaseous samples are prepared in a mixing line (primary vacuum) at room temperature. They are then deposited onto a 15 $\mathrm{K}$ cooled $1 \mathrm{~cm}^{2}$ copper surface at a rate of $0.4 \mathrm{mmol} \mathrm{s}^{-1}$ corresponding to a pressure within the vacuum chamber of $2 \times 10^{-6}$ mbar. $\mathrm{MeOH}, \mathrm{GA}, \mathrm{EG}, \mathrm{GCA}$ and GCO solid films were prepared by directly dosing them onto the sample holder in order to get spectroscopic references. The polyoxymethylene (POM) solid film used in this study as spectroscopic reference is obtained from the VUV photolysis at $13 \mathrm{~K}$ of pure $\mathrm{H}_{2} \mathrm{CO}$ ice (Butscher et al. 2016; Gerakines et al. 1996).

The copper sample holder is placed in a chamber, under high vacuum conditions (from $10^{-8}$ mbar at room temperature to $10^{-9}$ mbar at $15 \mathrm{~K}$ ). The system temperature is controlled by means of an ARS Cryo $4 \mathrm{~K}$ cold head combined with a resistive heater and a Lakeshore 336 temperature controller. Temperature changes are performed with a $2 \mathrm{~K} \mathrm{~min}^{-1}$ ramp.

The VUV photolysis step is performed at 15,50 or $90 \mathrm{~K}$ to change diffusion and reaction conditions within the ices. The three different temperatures of irradiation $(15,50$ and $90 \mathrm{~K})$ are separated in three distinct experiments (hereafter exp. 1, exp. 2 and exp. 3 respectively). Also, all these experiments were repeated us- 
ing ${ }^{13} \mathrm{C}$ formaldehyde. The VUV photons are generated from a microwave-discharged hydrogen-flow lamp T-type (MDHL T-type) with a running $\mathrm{H}_{2}$ pressure around 0.25 mbar. T-type MDLH and low $\mathrm{H}_{2}$ pressure increase the proportion of Lyman- $\alpha$ emission at $121.6 \mathrm{~nm}$ and can significantly decrease the contribution of molecular hydrogen emission around $160 \mathrm{~nm}$ (Chen et al. 2013).

The emitted flux from the plasma is transmitted through a $\mathrm{MgF}_{2}$ window and was measured to be $4.1 \pm 0.9 \times 10^{13}$ photons $\mathrm{cm}^{-2} \mathrm{~s}^{-1}$ using the known $\mathrm{H}_{2} \mathrm{CO}$ photodissociation cross section. This flux is about $10^{10}$ times higher than the UV secondary radiation flux observed in dense molecular clouds and represents about $10^{6}$ years of radiation per hour of laboratory experiment in such an environment.

The chemical composition of our ice analogues is analysed by infrared spectroscopy, using a Bruker Vertex 70 Fourier transform infrared (FTIR) spectrometer with a MCT detector in the reflectionabsorption mode. There is an angle of $18^{\circ}$ between the normal of the sample holder and the infrared beam. Resolution of the spectra is set at $1 \mathrm{~cm}^{-1}$ and each spectrum is averaged over 40 scans. 100 scans are recorded for the background with the same resolution.

Column densities $(N)$ in molec $\mathrm{cm}^{-2}$ are measured using $(N)=\frac{\int_{v_{1}}^{v_{2}} 2.3 A b s(v) \mathrm{d} v}{2 \cos (18) A}$, where $\int_{v_{1}}^{v_{2}} A b s(v) \mathrm{d} v$ is the integrated absorbance $\left(\mathrm{cm}^{-1}\right)$ of an infrared band whose boundaries are $v_{1}$ and $v_{2}$ and $A$ is the intrinsic band strength $\left(\mathrm{cm} \mathrm{molec}{ }^{-1}\right)$. The amount of formaldehyde is obtained from the band at $1499 \mathrm{~cm}^{-1}$ $\left(A=5.1 \times 10^{-18} \mathrm{~cm} \mathrm{molec}^{-1}\right.$, Bouilloud et al. (2015)). The amount of HCO is obtained from the band at $1848 \mathrm{~cm}^{-1}\left(A=1.5 \times 10^{-17}\right.$ $\mathrm{cm} \mathrm{molec}^{-1}$, Bennett $\&$ Kaiser (2007)). The amount of methanol is obtained from the band at $1029 \mathrm{~cm}^{-1}\left(A=1.5 \times 10^{-17} \mathrm{~cm} \mathrm{molec}^{-1}\right.$, Kerkhof et al. (1999)). The amount of ethylene glycol is obtained from the two bands at 1088 and $1047 \mathrm{~cm}^{-1}\left(A=3.9 \times 10^{-18} \mathrm{~cm}\right.$ molec $^{-1}$ each, Hudson et al. (2005)). The amount of glycolaldehyde is obtained from the band at $752 \mathrm{~cm}^{-1}\left(A=2.0 \times 10^{-18} \mathrm{~cm}\right.$ molec $^{-1}$, Hudson et al. (2005)). This specific band can be used from a pure GA spectrum after fitting the $\mathrm{C}=\mathrm{O}$ and $\mathrm{C}-\mathrm{O}$ GA $b$ ands of the experimental spectrum. It allows more precise measurement on GA quantification. Finally, the amount of POM is obtained from the band at $1109 \mathrm{~cm}^{-1}\left(A=9.7 \times 10^{-18} \mathrm{~cm} \mathrm{carbon}^{-1}\right.$, Schutte et al. (1993)). It is considered that experimental errors from band strength values are within 20\% (Bouilloud et al. 2015).

After irradiation at 15 (exp. 1), 50 (exp. 2) or $90 \mathrm{~K}$ (exp. 3), the samples are first heated to $110 \mathrm{~K}\left(2 \mathrm{~K} \mathrm{~min}^{-1}\right)$ to s tudy the effect of warming on the irradiated samples. We choose this specific t emperature s ince it is b elow the desorption temperature of COMs and formaldehyde which allows us to compare the COM abundances in different experiments without being affected by desorption processes. Samples are then heated to $160 \mathrm{~K}$ (around the water desorption temperature) at a rate of $2 \mathrm{~K} \mathrm{~min}^{-1}$ and are let at this temperature for $16 \mathrm{~h}$ in order to let water molecules to desorb in a gentle way. This step is mandatory to avoid intense COM codesorption with water during the Thermal Programmed Desorption (TPD). Nevertheless, during this process some organics are still lost along with water desorption but in less quantity than performing a continue TPD without stopping at $160 \mathrm{~K}$. The TPD is then continued from 160 to $300 \mathrm{~K}$ at the same rate set before. However, the different co-desorption processes (COMs with water and COMs with themselves) make impossible to use mass spectrometry in a quantitative way. The desorbing molecules are analysed using a Hiden analytical HAL 201 quadrupole mass spectrometer (QMS) with a $70 \mathrm{eV}$ electron impact source. The source is placed near the sam- ple holder so that pumping losses are minimized. Infrared spectra are recorded every $10 \mathrm{~K}$ during the TPD processes so that we can monitor samples by IR spectroscopy.

\section{RESULTS}

\subsection{Infrared qualitative study}

\subsubsection{Overview}

The mid-IR spectrum of the deposited $\mathrm{H}_{2} \mathrm{O} / \mathrm{H}_{2} \mathrm{CO}=3 / 1$ ice at $15 \mathrm{~K}$ is shown in Fig. 2b. The infrared spectrum is dominated by strong $\mathrm{OH}$ stretching mode of water and $\mathrm{C}=\mathrm{O}$ stretching mode of formaldehyde located at around 3400 and $1715 \mathrm{~cm}^{-1}$, respectively. All infrared band positions as well as their corresponding vibrational assignments for $\mathrm{H}_{2} \mathrm{O} / \mathrm{H}_{2}^{12} \mathrm{CO}$ and $\mathrm{H}_{2} \mathrm{O} / \mathrm{H}_{2}^{13} \mathrm{CO}$ ices are listed in Table 1. The samples are then irradiated at three different temperatures: 15 (exp. 1), 50 (exp. 2) and $90 \mathrm{~K}$ (exp. 3). Exp. 1 is directly irradiated after deposition during $170 \mathrm{~min}$. For the two other experiments, ices are first heated to 50 or $90 \mathrm{~K}$ at a $2 \mathrm{~K} \mathrm{~min}^{-1}$ rate before being irradiated during 80 and $40 \mathrm{~min}$ respectively. Irradiation times have been chosen so that $30 \pm 1 \%$ of the deposited formaldehyde is consumed. Since the products are mainly the same in the three experiments, only the $15 \mathrm{~K}$ irradiated one is presented here whereas exp. 2 and exp. 3 spectra can be found in appendix (Fig. A1 and A2). The infrared spectrum of exp. 1 is depicted in Fig. 2a where it is compared with the spectrum recorded before irradiation (Fig. $2 b$ ). Table 2 compiles the assignments of the newly formed species in both ${ }^{12} \mathrm{C}$ and ${ }^{13} \mathrm{C}$ experiments. The most striking features observed after irradiation located at 2342 and $2136 \mathrm{~cm}^{-1}$ are easily assigned to $\mathrm{CO}_{2}$ and $\mathrm{CO}$ respectively (Gerakines et al. 1996) (Table 2, Fig. 2). The formyl radical is also detected through its absorption band at $1846 \mathrm{~cm}^{-1}$ in ${ }^{12} \mathrm{C}$ and at $1804 \mathrm{~cm}^{-1}$ in ${ }^{13} \mathrm{C}$ experiment (Milligan \& Jacox 1969; Gerakines et al. 1996; Watanabe et al. 2007). In addition to the decomposition of precursors, small bands are also detected in the $\mathrm{C}=\mathrm{O}$ stretching region around $1700 \mathrm{~cm}^{-1}$ but are obscured by the precursor $\mathrm{H}_{2} \mathrm{CO}$ making this region difficult for spectroscopic sugar identification. However, several absorption bands are observed in the range $1200-900 \mathrm{~cm}^{-1}$ corresponding to $\mathrm{C}-\mathrm{O}$ stretching region where sugars and polyols are expected (Fig. 2). This region of interest deserve special attention since bands are very broad and complex suggesting several molecular carriers. Therefore, a deconvolution of the infrared absorption features in the range $1200-900 \mathrm{~cm}^{-1}$ has been performed and will be presented in the following section.

\subsubsection{Sugar and related compound region}

Fig. 3 shows a mathematical deconvolution of the COM region using ten Gaussians. The number and positions have been set using infrared contributions from reference spectra of species of interest. Four of these Gaussians belong to methanol, glycolaldehyde and ethylene glycol, three COMs which have been formed in previous experiments (Butscher et al. 2016). Five belong to the three carbon bearing products, glyceraldehyde and glycerol suspected to be formed. An additional Gaussian was necessary to reproduce the experimental spectrum. In other words, we have considered the main infrared bands from the suspected products. The choice of these products ( $\mathrm{MeOH}, \mathrm{GA}, \mathrm{EG}, \mathrm{GCA}$ and GCO) is also supported by mass spectrometry analyses and isotopic experiments (see "Mass spectrometry qualitative study" section). The main absorption features are: $\mathrm{MeOH}$ (green curve, $1029 \mathrm{~cm}^{-1}$ ), GA (purple, 
Table 1. Infrared absorption band positions $\left(\mathrm{cm}^{-1}\right)$ and assignments of $\mathrm{H}_{2} \mathrm{CO}$ in water at $15 \mathrm{~K}$.

\begin{tabular}{|c|c|c|c|c|}
\hline \multicolumn{2}{|c|}{$\bar{v}\left(\mathrm{~cm}^{-1}\right)$} & \multirow[t]{2}{*}{ Mode } & \multirow{2}{*}{$\begin{array}{c}\mathrm{A} \\
\left(\mathrm{cm} \mathrm{molec}{ }^{-1}\right)^{a}\end{array}$} & \multirow[t]{2}{*}{ Assign. } \\
\hline${ }^{12} \mathrm{C}$ & ${ }^{13} \mathrm{C}$ & & & \\
\hline $3675-3026$ & - & $v \mathrm{OH}$ & $2.2 \times 10^{-16}$ & $\mathrm{H}_{2} \mathrm{O}$ \\
\hline 2997 & 2959 & $\nu \mathrm{CO}+\rho \mathrm{CH}_{2}^{b}$ & $3.2 \times 10^{-18}$ & $\mathrm{H}_{2} \mathrm{CO}$ \\
\hline 2889 & 2860 & $v \mathrm{CH}_{2}(\mathrm{as})$ & $4.7 \times 10^{-18}$ & $\mathrm{H}_{2} \mathrm{CO}$ \\
\hline 2833 & 2817 & $v \mathrm{CH}_{2}(\mathrm{~s})$ & $1.3 \times 10^{-17}$ & $\mathrm{H}_{2} \mathrm{CO}$ \\
\hline 2724 & 2715 & $\delta \mathrm{CH}_{2}+\rho \mathrm{CH}_{2}^{b}$ & - & $\mathrm{H}_{2} \mathrm{CO}$ \\
\hline 1715 & 1678 & $v \mathrm{CO}$ & $1.6 \times 10^{-17}$ & $\mathrm{H}_{2} \mathrm{CO}$ \\
\hline 1667 & - & $\delta \mathrm{H}_{2} \mathrm{O}$ & $1.2 \times 10^{-17}$ & $\mathrm{H}_{2} \mathrm{O}$ \\
\hline 1496 & 1494 & $\delta \mathrm{CH}_{2}$ & $5.1 \times 10^{-18}$ & $\mathrm{H}_{2} \mathrm{CO}$ \\
\hline 1249 & 1237 & $\rho \mathrm{CH}_{2}$ & $1.5 \times 10^{-18}$ & $\mathrm{H}_{2} \mathrm{CO}$ \\
\hline 1178 & 1167 & $\omega \mathrm{CH}$ & $7.2 \times 10^{-19}$ & $\mathrm{H}_{2} \mathrm{CO}$ \\
\hline
\end{tabular}

Notes. $v$ : stretching; $\delta$ : bending; $\rho$ : rocking; $\omega$ : wagging; s: symetric; as: antisymetric. ${ }^{(a)}$ Bouilloud et al. (2015). ${ }^{(b)}$ Harvey \& Ogilvie (1962). Band strength errors are generally considered to be about $20 \%$ (Bouilloud et al. 2015).

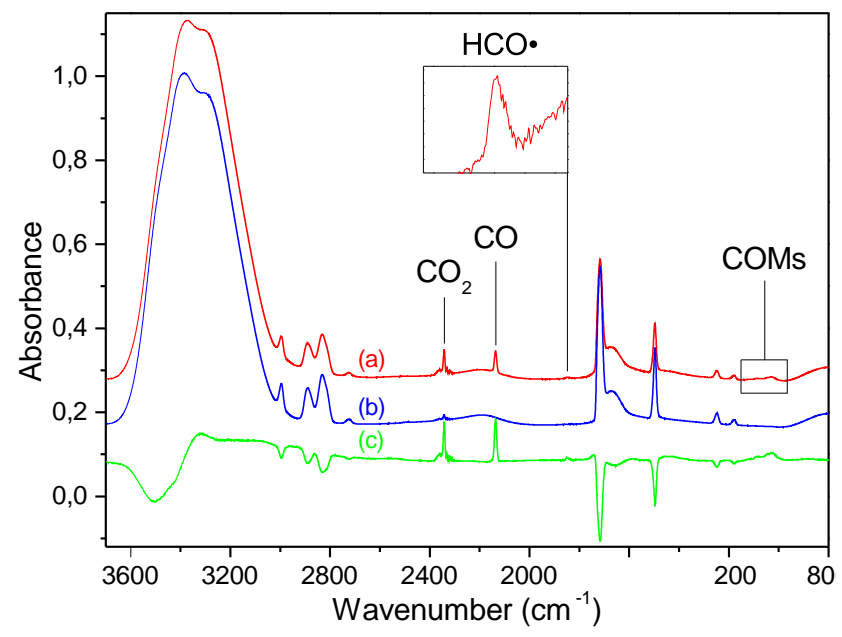

Figure 2. Infrared spectra of an $\mathrm{H}_{2} \mathrm{O} / \mathrm{H}_{2} \mathrm{CO}=3 / 1$ ice at $15 \mathrm{~K}$ before irradiation (b), after $170 \mathrm{~min}$ of VUV photolysis (a) and difference specrum ((c) $=(\mathrm{a})-(\mathrm{b}))$. Green spectrum has been multiplied by a factor of two.

$1109 \mathrm{~cm}^{-1}$ ), EG (red, 1047 and $1088 \mathrm{~cm}^{-1}$ ), GCA (cyan, 1134 and $1074 \mathrm{~cm}^{-1}$ ), GCO (orange, 1124, 1062 and $998 \mathrm{~cm}^{-1}$ ). Reference spectra are depicted in Fig. 3 panels $C$ and D where they can easily be compared with their corresponding Gaussian curves. All these Gaussian curves after fitting process are in good agreement with their corresponding absorption bands on the reference spectra as they are only shifted by few wavenumbers (less than $10 \mathrm{~cm}^{-1}$ ). For clarity reasons, COMs are split in two categories in Fig. 3. $\mathrm{C}_{1}$ and $\mathrm{C}_{2} \mathrm{COMs}(\mathrm{MeOH}, \mathrm{GA}$ and $\mathrm{EG}$ ) are displayed in panel $\mathrm{A}$ (Gaussian curves) and $\mathrm{C}$ (reference spectra) while $\mathrm{C}_{3} \mathrm{COMs}$ (GCA and GCO) are depicted in panel B (Gaussian curves) and D (reference spectra). We chose to use only one Gaussian curve for GA (the more intense at $\left.1109 \mathrm{~cm}^{-1}\right)$ as its two other bands $\left(1075\right.$ and $\left.1046 \mathrm{~cm}^{-1}\right)$ tend to disappear when the GA molecule environment changes as Fig. A3 in appendix section shows it. The Gaussian curve at $1014 \mathrm{~cm}^{-1}$ in ${ }^{12} \mathrm{C}$ experiments $\left(985 \mathrm{~cm}^{-1}\right.$ in ${ }^{13} \mathrm{C}$ experiment) labelled with a star is not yet attributed.

We also "fitted" the experimental infrared spectrum recorded
Table 2. Infrared absorption band positions $\left(\mathrm{cm}^{-1}\right)$ and assignments of formed species.

\begin{tabular}{|c|c|c|c|c|c|}
\hline \multicolumn{2}{|c|}{$\bar{v}\left(\mathrm{~cm}^{-1}\right)$} & \multirow[t]{2}{*}{ Mode } & \multirow{2}{*}{$\begin{array}{c}\mathrm{A} \\
(\mathrm{cm} \mathrm{molec}-1)\end{array}$} & \multirow[t]{2}{*}{ Assign. } & \multirow[t]{2}{*}{ ref. } \\
\hline${ }^{12} \mathrm{C}$ & ${ }^{13} \mathrm{C}$ & & & & \\
\hline 2342 & 2275 & $v \mathrm{C}=\mathrm{O}$ & $7.1 \times 10^{-17}$ & $\mathrm{CO}_{2}$ & $a$ \\
\hline 2136 & 2088 & $v \mathrm{C} \equiv \mathrm{O}$ & $1.7 \times 10^{-17}$ & $\mathrm{CO}$ & $b$ \\
\hline 1848 & 1810 & $v \mathrm{C}=\mathrm{O}$ & $1.5 \times 10^{-17}$ & $\mathrm{HCO}$ & $c$ \\
\hline 1745 & 1721 & $v \mathrm{C}=\mathrm{O}$ & $2.6 \times 10^{-17}$ & $\mathrm{GA}^{k}$ & $d$ \\
\hline 1134 & $1117^{i}$ & $\nu \mathrm{C}-\mathrm{O}$ & $?$ & GCA & $f$ \\
\hline $1124^{i}$ & $1104^{i}$ & $v \mathrm{C}-\mathrm{O}$ & $?$ & GCO & $f$ \\
\hline 1109 & $1092^{i}$ & $v \mathrm{C}-\mathrm{O}$ & $8.1 \times 10^{-18}$ & GA & $d$ \\
\hline 1109 & 1089 & $v \mathrm{C}-\mathrm{O}$ & $* 9.7 \times 10^{-18}$ & POM & $g$ \\
\hline 1088 & 1065 & $v \mathrm{C}-\mathrm{O}$ & $3.9 \times 10^{-18}$ & EG & $d$ \\
\hline $1074^{i}$ & $1049^{i}$ & $v \mathrm{C}-\mathrm{O}$ & $?$ & GCA & $f$ \\
\hline $1062^{i}$ & $1038^{i}$ & $v \mathrm{C}-\mathrm{O}$ & $?$ & $\mathrm{GCO}$ & $f$ \\
\hline 1047 & $1024^{i}$ & $v \mathrm{C}-\mathrm{O}$ & $3.9 \times 10^{-18}$ & EG & $d$ \\
\hline 1029 & 1005 & $v \mathrm{C}-\mathrm{O}$ & $1.5 \times 10^{-17}$ & $\mathrm{CH}_{3} \mathrm{OH}$ & $e$ \\
\hline $1014^{i}$ & $985^{i}$ & $v \mathrm{C}-\mathrm{O}$ & $?$ & $?$ & $f$ \\
\hline 998 & 974 & $v \mathrm{C}-\mathrm{O}$ & $?$ & GCO & $f$ \\
\hline $936^{j}$ & $916^{j}$ & $v \mathrm{C}-\mathrm{O}$ & $* 3.0 \times 10^{-17}$ & POM & $g$ \\
\hline $915^{j}$ & $887^{j}$ & $v \mathrm{C}-\mathrm{O}$ & $* 3.0 \times 10^{-17}$ & POM & $g$ \\
\hline $888^{j}$ & $878^{j}$ & $\rho \mathrm{CH}_{2}$ & $?$ & EG & $h$ \\
\hline $867^{j}$ & $?$ & $\rho \mathrm{CH}_{2}$ & $?$ & EG & $h$ \\
\hline
\end{tabular}

Notes. $v$ : stretching. $\rho$ : rocking. ${ }^{(*)}$ These values are in $\mathrm{cm}$ carbon $^{-1}$, see Schutte et al. (1993). ${ }^{(a)}$ Gerakines et al. (1996). ${ }^{(b)}$ Hudson \& Moore (1999). ${ }^{(c)}$ Bennett \& Kaiser (2007). ${ }^{(d)}$ Hudson et al. (2005). ${ }^{(e)}$ Kerkhof et al. (1999). ${ }^{(f)}$ This work. ${ }^{(g)}$ Schutte et al. (1993), band strengths are displayed in cm carbon ${ }^{-1} .{ }^{(h)}$ Buckley \& Giguère (1967). ${ }^{(i)}$ These bands are not directly observable on the spectrum of the $\mathrm{H}_{2} \mathrm{O} / \mathrm{H}_{2} \mathrm{CO}$ irradiated sample so they are determined using a Gaussian fitting. All band positions for ${ }^{13} \mathrm{C}$ were determined using a deconvolution with Gaussian curves shown in appendix (Fig. A9). ${ }^{(j)}$ These bands are only detected after water desorption at $160 \mathrm{~K}$. ${ }^{(k)}$ Minor contribution of $\mathrm{C}=\mathrm{O}$ stretching mode of GCA can also contribute to this feature. Band strength errors are generally considered to be about 20\% (Bouilloud et al. 2015).

after irradiation using another technique we previously successfully used (Butscher et al. 2015). Basically, we reconstruct in the C-O stretching region (COM region) the experimental spectrum with a linear combination of our infrared reference spectra of observed products $\mathrm{MeOH}, \mathrm{EG}, \mathrm{GA}, \mathrm{GCA}, \mathrm{GCO}$ and POM (Fig. 4). Fig. 4 shows all reference spectra of $\mathrm{MeOH}, \mathrm{EG}, \mathrm{GA}, \mathrm{GCA}, \mathrm{GCO}$ and POM together with the experimental spectrum of a $15 \mathrm{~K}$ VUV photolysed ice and the reconstructed infrared spectrum. It is important to note that no mathematical fit has been used here. We first manually adjust intensities of $\mathrm{MeOH}$, GA and EG (and POM for high irradiation temperatures) as we know they are formed in such experiments (Butscher et al. 2016). Constraints on GA and POM quantities can be made using other available bands. We used the band at $1751 \mathrm{~cm}^{-1}$ to adjust the GA spectrum intensity (see "experimental" section for details). POM quantification is also possible by IR spectroscopy with its characteristic bands at 915 and $936 \mathrm{~cm}^{-1}$, observable after desorption of water (see Fig. A4 in appendix section). We then add GCO and GCA in small quantities to reproduce as well as possible the experimental spectrum. Caution has to be taken because the six reference spectra depicted here were recorded using pure species, which is not the case in the experiments (complex mixture). Also, absolute species quantities are different between reference and experimental spectra. Spectrum appearance depends 


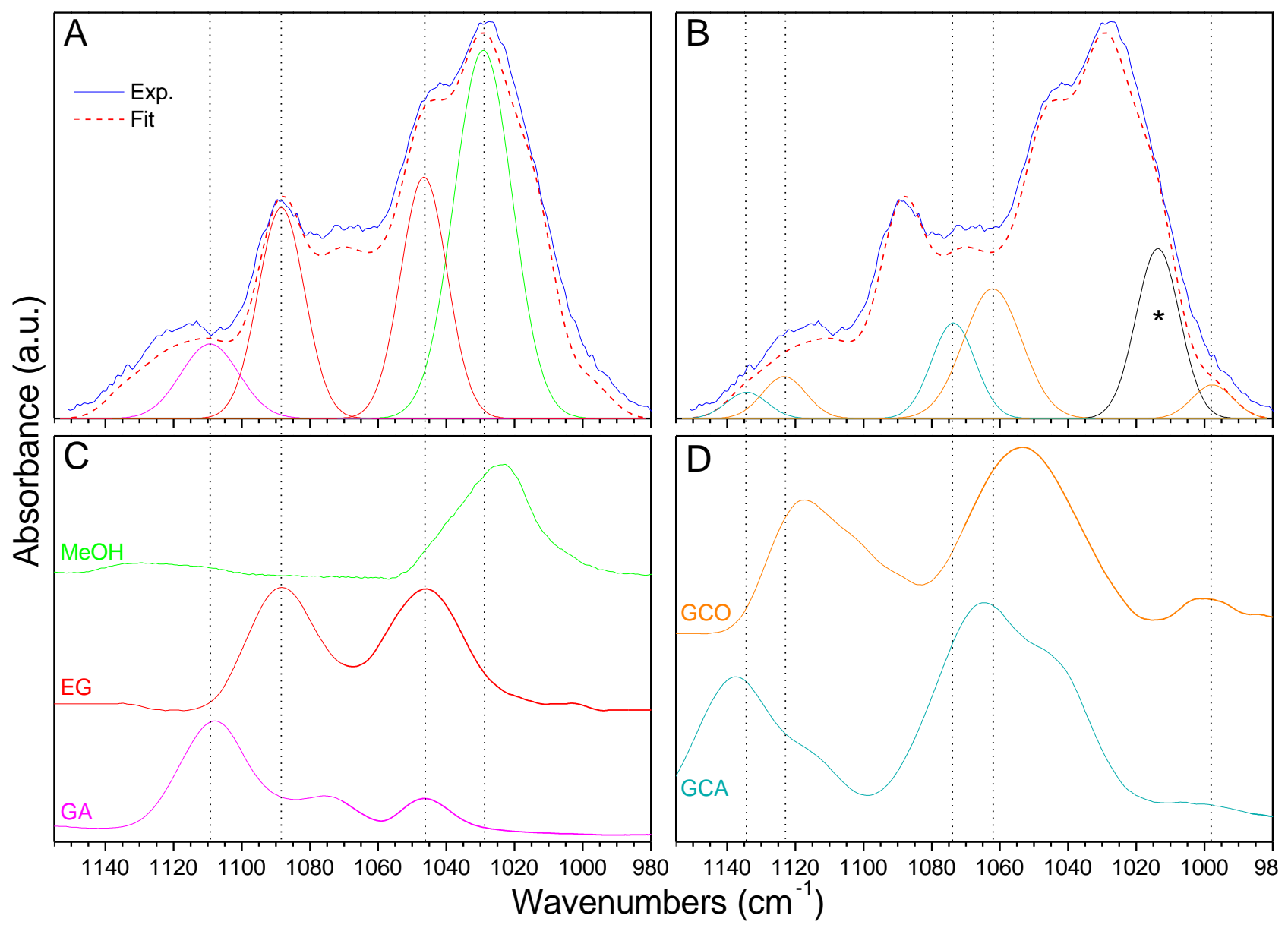

Figure 3. Infrared spectrum of a $15 \mathrm{~K}$ VUV irradiated $\mathrm{H}_{2} \mathrm{O} / \mathrm{H}_{2} \mathrm{CO}=3 / 1$ ice recorded at $15 \mathrm{~K}$ (solid blue curve) compared to a deconvoluted infrared spectrum (dashed red curve) composed of 10 Gaussian curves. Panel A: Gaussian curves corresponding to $\mathrm{C}_{1}$ and $\mathrm{C}_{2} \mathrm{COMs}$ : GA, EG and MeOH. Panel B: Gaussian curves corresponding to $\mathrm{C}_{3} \mathrm{COMs}$ : GCA and GCO. The Gaussian curve labelled with a star is not attributed. Panel C: Infrared reference spectra of MeOH, EG and GA recorded at $15 \mathrm{~K}$. Panel D: Infrared reference spectra of GCO and GCA recorded at $90 \mathrm{~K}$.

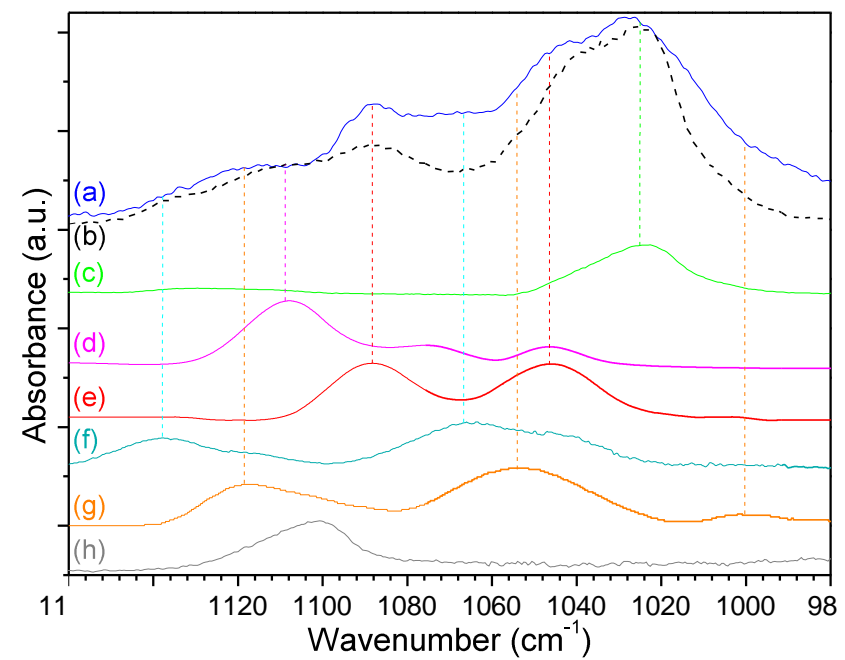

Figure 4. (a) Infrared spectrum of a 170 min VUV irradiated $\mathrm{H}_{2} \mathrm{O} / \mathrm{H}_{2} \mathrm{CO}=$ $3 / 1$ ice at $15 \mathrm{~K}$ and (b) reconstructed infrared spectrum built as a linear combination of the reference spectra compared to reference spectra of methanol (c), glycolaldehyde (d), ethylene glycol (e), glyceraldehyde (f), glycerol (g) and polyoxymethylene (h). widely on molecular quantity and environment; band positions and intensities can be affected accordingly (Fig. A3). However, the acceptable match between both experimental and summed spectra suggests that the right products - $\mathrm{MeOH}, \mathrm{GA}, \mathrm{EG}, \mathrm{GCA}, \mathrm{GCO}$ and POM (when formed)- have been used to reproduce the experimental spectrum.

\subsection{Mass spectrometry qualitative study}

Mass spectrometry was performed to confirm the results obtained using infrared spectroscopy. We adopted the same strategy as with infrared spectroscopy for product identification by recording our own reference mass spectra. Fig. 5 shows the TPD traces from the $2 \mathrm{~K} \mathrm{~min}^{-1}$ heating of pure samples of GCO and GCA recorded with our experimental setup. Mass spectra were also recorded at the desorption maximum peak of each species and are displayed in the right panel of Fig. 5. Only $\mathrm{m} / z=61$ and $\mathrm{m} / z=72$ fragments are displayed as they are characteristic of these two species. It clearly appears that pure GCA and pure GCO desorb around 220 and $250 \mathrm{~K}$ respectively. These two desorption temperatures are in good agreement with the literature as GCA was reported to desorb around 230 $\mathrm{K}$ and GCO around $240 \mathrm{~K}$ (McManus et al. 2014; Maity et al. 2015; Paardekooper et al. 2016). As expected, for pure molecules, GCA and GCO desorption occurs latter than GA $(180 \mathrm{~K})$ and EG (225 


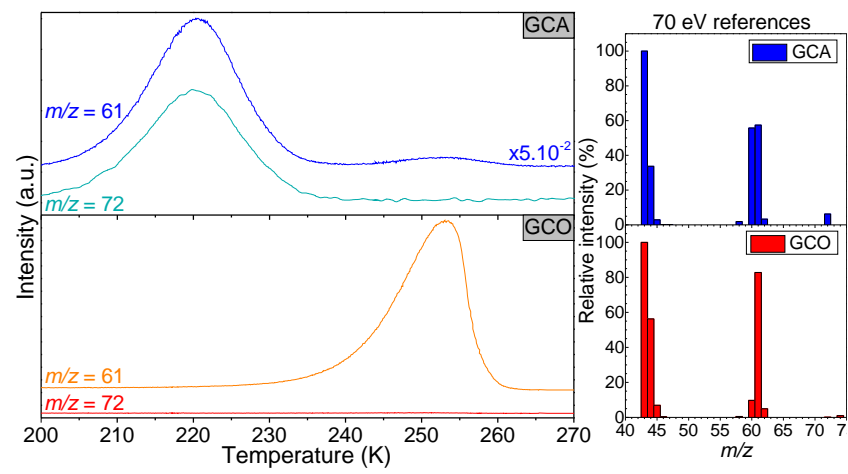

Figure 5. TPD traces $\left(2 \mathrm{~K} \mathrm{~min}^{-1}\right)$ of pure GCA and GCO solid reference films. Reference mass spectra $(70 \mathrm{eV})$ of GCA $(220 \mathrm{~K})$ and GCO $(253 \mathrm{~K})$ are displayed on the right pannel.

K) desorption as the former are heavier molecules (Butscher et al. 2015). Since the desorption temperatures and the structures of all these molecules are close and that many interactions are possible between them, co-desorption is expected to occur during the TPD experiments of complex samples.

After the photolysis, the water matrix is gently desorbed at 160 $\mathrm{K}$ for 16 hours and then a TPD is performed from 160 to $300 \mathrm{~K}$ at a rate of $2 \mathrm{~K} \mathrm{~min}^{-1}$. Even if the water matrix is gently desorbed at 160 $\mathrm{K}$, a non-negligible quantity of COMs is lost during this process (including GCA and GCO). In addition, co-desorption between GA, EG, GCA and GCO is observed between 160 and $210 \mathrm{~K}$. As signal is abundant and difficult to analyze in this range, we decided to focus on higher temperatures $(210-300 \mathrm{~K})$ where GCA, GCO and POM are clearly desorbing. Additionally, there is no $\mathrm{MeOH}$, EG and GA desorption in this range of temperature as it occurs before $210 \mathrm{~K}$. TPD curves from 210 to $300 \mathrm{~K}$ for the three experiments are showed in Fig. 6. The $\mathrm{m} / z=61, \mathrm{~m} / \mathrm{z}=72$ and $\mathrm{m} / \mathrm{z}=47$ fragments are characteristic of GCO, GCA and POM and are displayed for 15,50 and $90 \mathrm{~K}$ irradiated experiments. The $\mathrm{m} / \mathrm{z}=47$ fragment is necessary to differentiate GCO and POM as these two species share the $m / z=61$ fragment whereas only POM gives a fragment at $m / z=47$ (Duvernay et al. 2014; Butscher et al. 2019). POM was reported to desorb in a wide range of temperatures (200 to $250 \mathrm{~K}$ ) (Duvernay et al. 2014; Butscher et al. 2019) because of chain length distribution which confirms that high mass POM molecules are not formed in exp. 1 as $\mathrm{m} / z=47$ and $\mathrm{m} / z=61$ fragment desorptions only occur at 220 and $225 \mathrm{~K}$ respectively. The $\mathrm{m} / \mathrm{z}=47$ fragment could come from short-chain POM of maximum two or three carbons considering the low and small range of desorption temperature. The $\mathrm{m} / \mathrm{z}=61$ and $\mathrm{m} / \mathrm{z}=72$ fragments around $225 \mathrm{~K}$ belong to GCA as Fig. 5 shows it. From this, we can conclude that GCA is formed in all three experiments as the $m / z=61$ fragment is always detected around $225 \mathrm{~K}$ even if the $\mathrm{m} / z=72$ fragment is not. One has to keep in mind that GCA should be formed in a very low quantity. In addition, in ${ }^{13} \mathrm{C}$ experiments, $\mathrm{m} / \mathrm{z}=75$ fragment is detected for exp. 2 and exp. 3 which confirms that GCA can be formed in such experiments (Fig. A8 in Appendix).

In the case of POM, we clearly see that $\mathrm{m} / \mathrm{z}=47$ and $\mathrm{m} / \mathrm{z}$ $=61$ fragments are detected in exp. 2 and exp. 3 between 235 and $270 \mathrm{~K}$ which is characteristic of high mass POM desorption. Moreover, the $\mathrm{m} / \mathrm{z}=47$ fragment is nearly not detected around $220 \mathrm{~K}$ in these experiments which makes consistent its assignment to short-chain POM in this range of temperature. The chain mass distribution seems to highly depend on the irradiation temperature;

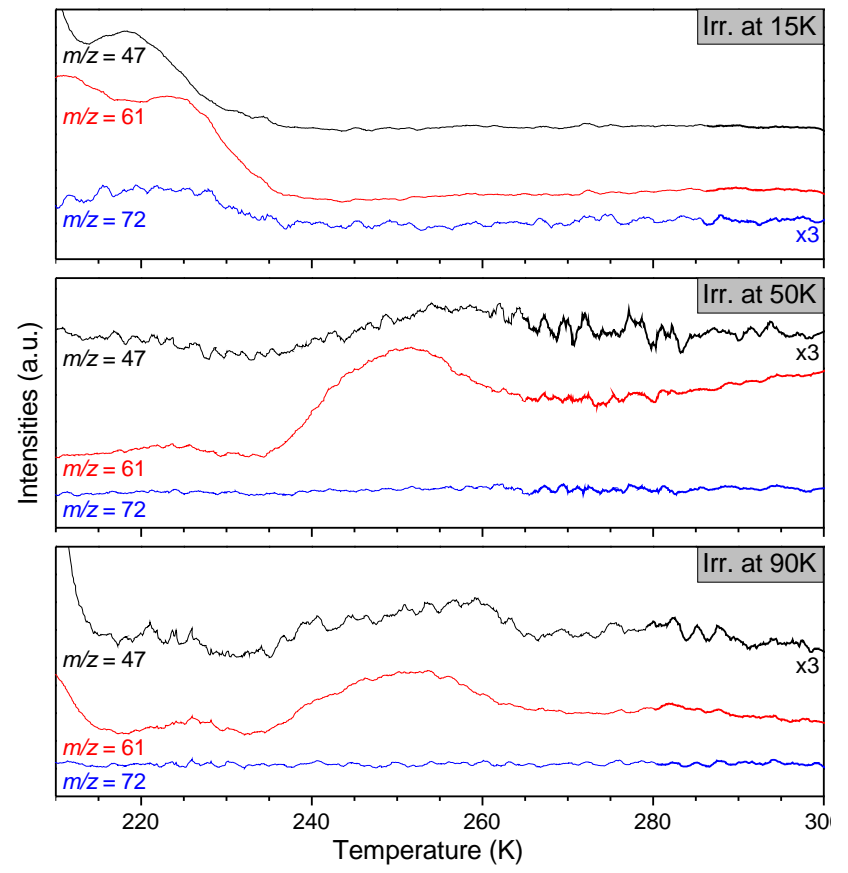

Figure 6. TPD traces $\left(2 \mathrm{~K} \mathrm{~min}^{-1}\right)$ of the 15,50 and $90 \mathrm{~K}$ VUV irradiated $\mathrm{H}_{2} \mathrm{O} / \mathrm{H}_{2} \mathrm{CO}=3 / 1$ ices. Fragments of $m / z=47(\mathrm{POM}), 61(\mathrm{POM} / \mathrm{GCO} / \mathrm{GCA})$ and 72 (GCA) are displayed for each experiment.

at low irradiation temperature ( $15 \mathrm{~K}$ in this work) only short-chain polymer are detected whereas, at higher temperature of irradiation (50 or $90 \mathrm{~K}$ in this work), higher mass POM molecules (longer chain polymer) are detected.

In the case of GCO, mass spectrometry does not give any hint of its formation for exp. 1 but the $\mathrm{m} / z=63$ fragment (GCO) in the corresponding ${ }^{13} \mathrm{C}$ experiment (see Fig. A7) is detected while the $m / z=48$ fragment (POM) is not. The non-detection of GCO in the ${ }^{12} \mathrm{C}$ exp. 1 could be explained by its desorption together with other COMs and water between 160 and $210 \mathrm{~K}$. However, in the two other experiments, GCO ${ }^{12} \mathrm{C}$ can be found from the $\mathrm{m} / \mathrm{z}=61$ fragment, which is centered at $250 \mathrm{~K}$ and is consistent with our reference (Fig. 5). The promoted POM formation when samples are irradiated at 50 and $90 \mathrm{~K}$ may trap GCO molecules which prevents them to co-desorb with water and other COMs between 160 and $210 \mathrm{~K}$. However, it can co-desorb along with POM between 235 and $270 \mathrm{~K}$ since their desorption temperatures are close.

The formation of other stable products such as carbonic acid and formic acid cannot be excluded but they are not discussed here because of their low amount and that they desorb before $210 \mathrm{~K}$. These molecules were already the focus of attention in a previous paper (Butscher et al. 2016).

\subsection{Quantitative study}

\subsubsection{Product quantification}

Abundances of $\mathrm{CO}_{2}, \mathrm{CO}$ and $\mathrm{HCO}$ have been calculated using band strengths of their characteristic absorption bands at 2342, 2136 and $1846 \mathrm{~cm}^{-1}$ respectively (Table 2). Abundances of COMs confirmed by both infrared spectroscopy and mass spectrometry (MeOH, GA, EG, GCA, GCO and POM) have been determined using two different methods. The first quantification is done by using deconvoluted 


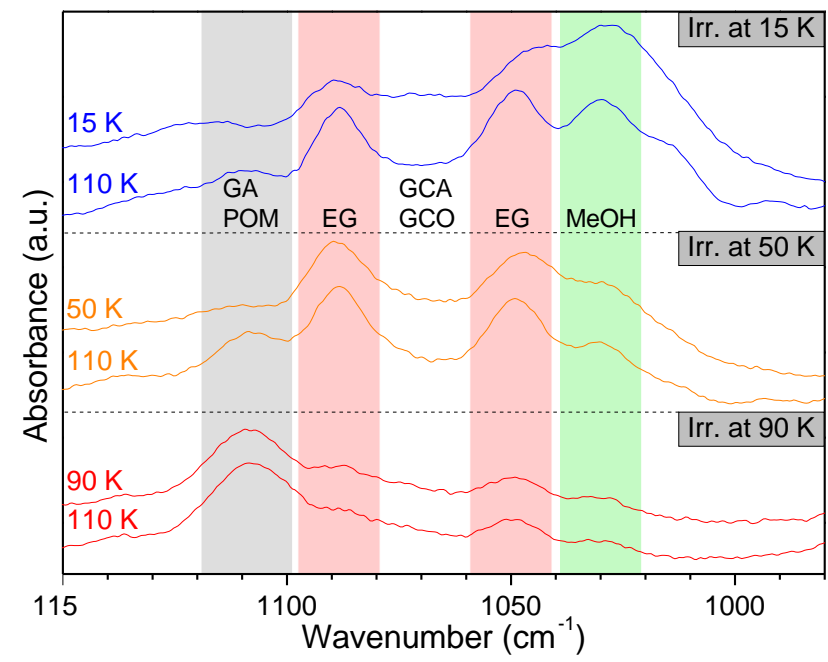

Figure 7. Infrared spectra in C-O stretching region for the three experiments irradiated at 15 (blue), 50 (orange) and $90 \mathrm{~K}$ (red). Spectra are recorded the temperature of irradiation for each experiment as well as at $110 \mathrm{~K}$. Species are mentioned at their maximum of absorption. There is no modification on the scale in this figure.

infrared spectra shown in Fig. 3 or in Fig. A5 in appendix. A second one is done from reference spectra of pure species used to build manual fits (Fig. 4 and Fig. A6 in appendix) of experimental spectra. Both methods present errors and uncertainties because the experimental spectra are composed of signal which are neither perfect Gaussian curves nor pure species signals. However, this twomanner determination gives an idea on the order of magnitude for errors made. The results obtained by these two methods are averaged and the error is determined by the difference between the upper determination result and the average value. Also, it may exist an error coming from the direct measurement of peak areas. We estimated that it cannot exceed $10 \%$, so this $10 \%$ error is added on each result. Since infrared band strengths of GCA and GCO are not available in the literature (that is to say: no column density available), we only reported their integrated absorbance. Table 3 lists the abundances (when available) of the formed species: $\mathrm{CO}, \mathrm{HCO}, \mathrm{MeOH}, \mathrm{GA}, \mathrm{EG}$, GCA, GCO and POM for the three experiments (irradiation at 15, 50 and $90 \mathrm{~K}$ ). Effects of irradiation temperature are discussed in the following section.

\subsubsection{Irradiation temperature effects}

Fig. 7 shows the COM region for all three experiments directly after irradiation $(15,50$ and $90 \mathrm{~K})$ and after warming of the sample to 110 $\mathrm{K}$ for each experiment. It is clear that the irradiation temperature plays an important role in branching ratios and diffusion processes. An important extinction of methanol is observed with the increase of temperature (Fig. 7, Table 3). EG is nearly disappearing as well when irradiation temperature is $90 \mathrm{~K}$ (Fig. 7, Table 3). However, formation of GA seems to be favored when temperature of irradiation increases. The most interesting result is the formation of POM (characteristic bands : $1109 \mathrm{~cm}^{-1}$ (most intense) or $936 \mathrm{~cm}^{-1}$ after desorption of water) at high temperature of photolysis which is partly responsible of the intense band around $1110 \mathrm{~cm}^{-1}$ for the 90 $\mathrm{K}$ irradiated ice. However, POM is not detected by infrared spectroscopy at low temperature of photolysis which could be explained by the low diffusion of formaldehyde into a water ice at such low temperatures (Mispelaer et al. 2013).
3.3.2.1 CO. As expected, CO represents one of the main carbon transformation pathways from photolysed formaldehyde as it reaches up to $25 \%$ of the consumed $\mathrm{H}_{2} \mathrm{CO}$ (Table 3). When irradiation temperature is increased, $\mathrm{CO}$ formation decreases which can be explained by its low sublimation temperature of about $50 \mathrm{~K}$ (Bennett \& Kaiser 2007).

3.3.2.2 $\mathrm{CO}_{2}$. Carbon dioxide follows the exact same trend as $\mathrm{CO}$; its abundance of $3.6 \%$ in exp. 1 decreases as the irradiation temperature increases (Table 3 ). This can easily be explained by the fact that $\mathrm{CO}_{2}$ is formed in the ice by the reaction $\mathrm{CO}+\mathrm{OH}$ (Garrod \& Pauly 2011). CO being depleted at 50 and $90 \mathrm{~K}$ by desorption, $\mathrm{CO}_{2}$ formation is hampered. $\mathrm{CO}_{2}$ can also be formed by the reaction $\mathrm{O}+\mathrm{CO}$ (see "chemical network" section).

3.3.2.3 MeOH. The amount of methanol is $10.3 \%$ in exp. 1 and has the same behaviour as carbon monoxide but $\mathrm{MeOH}$ desorption temperature is much higher (115 to $150 \mathrm{~K}$ depending on the environment and quantity) (Bennett \& Kaiser 2007; Butscher et al. 2016). As a result, the lower quantity of $\mathrm{MeOH}$ when the irradiation temperature is increased cannot be explained by its sublimation. However, $\mathrm{H}$-atoms desorb more easily when the temperature rises as their ability to diffuse is greatly enhanced with the temperature. It should disfavor hydrogenation processes and thus, formation of methanol. In addition, $\mathrm{MeOH}$ quantity lightly decreases when the temperature is increased from the initial irradiation temperature to $110 \mathrm{~K}$. This could be explained by its consumption as a hydrogen donor to perform $\mathrm{H}$-abstraction processes when $\mathrm{H}$-atoms begin to lack in the sample.

3.3.2.4 HCO. Regarding formyl radical, its detected quantity is divided by a factor of two at $50 \mathrm{~K}(1.2 \%)$ compared to $15 \mathrm{~K}(2 \%)$, indicating an increased mobility of $\mathrm{HCO}$ radical at $50 \mathrm{~K}$ compared to lower temperatures. At $90 \mathrm{~K}, \mathrm{HCO}$ is no longer detected but we still observe products involving it as a reactant such as GA. It means that at such a high temperature, its lifetime is shorter than the acquisition of a spectrum.

3.3.2.5 GA. Glycolaldehyde is clearly more formed when the irradiation temperature is increased as it represents from $4.5 \%$ of consumed formaldehyde at $15 \mathrm{~K}$ up to $11.5 \%$ at $90 \mathrm{~K}$. A great part of GA seems to come from warming processes following the photolysis except for exp. 3 where the two measured GA quantities are equal, within the error margins (Table 3, Fig. 7).

3.3.2.6 EG. Ethylene glycol, the second species to be formed in exp. 1, has a behavior more surprising. It is optimally produced when irradiation temperature is set to $50 \mathrm{~K}$ and almost no longer formed in $90 \mathrm{~K}$ photolysed experiments (Table 3, Fig. 7). This may come from the low quantity of available hydrogen at high temperatures as EG needs $\mathrm{CH}_{2} \mathrm{OH}$ radicals to be formed and as this radical is produced from formaldehyde hydrogenation (reaction 1).

3.3.2.7 POM. The most striking result is that polyoxomethylene is formed with elevation of the irradiation temperature. It seems that the higher the temperature of irradiation, the greater the quantity of POM, reaching $4.9 \%$ in exp. 3 . This result could be explained by the increased mobility of formaldehyde with temperature (Mispelaer et al. 2013) and by the decline of hydrogenation processes lowering termination process probability. Quantity of formed POM is directly taken as a function of the number of $\mathrm{C}$ atoms (the used band strength value is in $\mathrm{cm}_{\text {carbon }}{ }^{-1}$ ) needed to produce it (Schutte et al. 1993). 
Table 3. Abundances of formed species during VUV photolysis at 15,50 or $90 \mathrm{~K}$ for $\mathrm{H}_{2} \mathrm{O} / \mathrm{H}_{2} \mathrm{CO}=3 / 1$ ices

\begin{tabular}{|c|c|c|c|c|c|c|c|c|c|c|c|c|}
\hline \multirow[b]{3}{*}{ Species } & \multicolumn{4}{|c|}{ Exp. 1} & \multicolumn{4}{|c|}{ Exp. 2} & \multicolumn{4}{|c|}{ Exp. 3} \\
\hline & \multicolumn{2}{|c|}{$15 \mathrm{~K}$} & \multicolumn{2}{|c|}{$110 \mathrm{~K}$} & \multicolumn{2}{|c|}{$50 \mathrm{~K}$} & \multicolumn{2}{|c|}{$110 \mathrm{~K}$} & \multicolumn{2}{|c|}{$90 \mathrm{~K}$} & \multicolumn{2}{|c|}{$110 \mathrm{~K}$} \\
\hline & $\mathrm{N}^{*}$ & $(\%)$ & $\mathrm{N}^{*}$ & $(\%)$ & $\mathrm{N}^{*}$ & $(\%)$ & $\mathrm{N}^{*}$ & $(\%)$ & $\mathrm{N}^{*}$ & $(\%)$ & $\mathrm{N}^{*}$ & $(\%)$ \\
\hline $\mathrm{CO}$ & $35.0 \pm 4.0$ & $25.0 \pm 2.5$ & $22.0 \pm 2.0$ & $15.7 \pm 1.6$ & $21.0 \pm 2.0$ & $19.1 \pm 1.9$ & $14.0 \pm 1.0$ & $12.7 \pm 1.3$ & $5.7 \pm 0.6$ & $5.7 \pm 0.6$ & $4.5 \pm 0.5$ & $4.5 \pm 0.5$ \\
\hline $\mathrm{CO}_{2}$ & $5.0 \pm 0.5$ & $3.6 \pm 0.4$ & $4.1 \pm 0.4$ & $2.9 \pm 0.3$ & $3.6 \pm 0.4$ & $3.3 \pm 0.3$ & $3.1 \pm 0.3$ & $2.8 \pm 0.3$ & $0.9 \pm 0.1$ & $0.9 \pm 0.1$ & $0.8 \pm 0.1$ & $0.8 \pm 0.1$ \\
\hline $\mathrm{MeOH}$ & $15.0 \pm 4.0$ & $10.3 \pm 2.8$ & $9.6 \pm 1.4$ & $6.8 \pm 1.0$ & $6.5 \pm 0.8$ & $5.9 \pm 0.7$ & $4.6 \pm 1.0$ & $4.2 \pm 0.9$ & $1.6 \pm 0.5$ & $1.6 \pm 0.3$ & $1.3 \pm 0.3$ & $1.3 \pm 0.3$ \\
\hline $\mathrm{HCO}$ & $2.8 \pm 0.3$ & $2.0 \pm 0.2$ & n.d. & 0 & $1.3 \pm 0.1$ & $1.2 \pm 0.1$ & n.d. & 0 & n.d. & 0 & n.d. & 0 \\
\hline EG & $22.0 \pm 3.0$ & $15.4 \pm 1.9$ & $31.0 \pm 7.0$ & $22.2 \pm 5.1$ & $30.0 \pm 9.0$ & $26.8 \pm 8.6$ & $29.0 \pm 6.0$ & $25.9 \pm 5.8$ & $7.8 \pm 2.8$ & $7.8 \pm 2.8$ & $6.8 \pm 2.6$ & $6.8 \pm 2.6$ \\
\hline GA & $6.3 \pm 0.9$ & $4.5 \pm 0.7$ & $10.0 \pm 2.0$ & $7.1 \pm 1.4$ & $6.5 \pm 0.7$ & $5.9 \pm 0.6$ & $14.0 \pm 2.0$ & $12.7 \pm 2.2$ & $12.0 \pm 3.0$ & $11.5 \pm 2.7$ & $13.0 \pm 2.0$ & $12.5 \pm 1.8$ \\
\hline POM & n.d. & 0 & n.d. & 0 & $0.5 \pm 0.1$ & $0.5 \pm 0.1$ & $0.8 \pm 0.1$ & $0.8 \pm 0.1$ & $4.9 \pm 0.5$ & $4.9 \pm 0.5$ & $4.7 \pm 0.5$ & $4.7 \pm 0.5$ \\
\hline GCA & $0.041 \pm 0.004$ & - & $0.052 \pm 0.005$ & - & $0.039 \pm 0.004$ & - & $0.034 \pm 0.003$ & - & $0.028 \pm 0.003$ & - & $0.026 \pm 0.003$ & - \\
\hline $\mathrm{GCO}$ & $0.058 \pm 0.006$ & - & $0.095 \pm 0.01$ & - & $0.070 \pm 0.007$ & - & $0.035 \pm 0.004$ & - & $0.023 \pm 0.002$ & - & $0.023 \pm 0.002$ & - \\
\hline
\end{tabular}

Notes. The times of photolysis are 170,80 and $40 \mathrm{~min}\left(4.2 \times 10^{17}, 2.0 \times 10^{17}\right.$ and $9.8 \times 10^{16}$ photons.cm ${ }^{-2}$ respectively $)$ for exp. 1 , exp. 2 and exp. 3 respectively. The total amounts of consumed $\mathrm{H}_{2} \mathrm{CO}\left(\mathrm{N}_{c}\left(\mathrm{H}_{2} \mathrm{CO}\right)\right)$ are $1.4 \times 10^{17}, 1.1 \times 10^{17}$ and $1.0 \times 10^{17} \mathrm{molec} \mathrm{cm}^{-2}$ respectively and represent $30 \pm 1 \%$ of the initial formaldehyde quantity for each experiment. The quantities of consumed formaldehyde during heating processes from irradiation temperature to $110 \mathrm{~K}$ are: $1.2 \times 10^{17}, 9.3 \times 10^{16}$ and $4.6 \times 10^{16}$ molecule $\mathrm{cm}^{-2}$ for exp. 1, exp. 2 and exp. 3 respectively. Some formaldehyde is lost by desorption as its sublimation temperature is about $110 \mathrm{~K}$ (Noble et al. 2012). The yields have been calculated as follows: $(\%)=\mathrm{N}(\mathrm{X}) / \mathrm{N}_{c}\left(\mathrm{H}_{2} \mathrm{CO}\right)$. POM yield is expressed as a function of consumed carbon atom (Schutte et al. 1993). Uncertainties have been determined by averaging two different quantification methods (manual fit and Gaussian fit) and taking into account a $10 \%$ error for peak area measurements. ${ }^{(*)} \mathrm{N}$ is expressed in $10^{15}$ molecule cm ${ }^{-2}$ except for POM where it is in $10^{15}$ carbon $\mathrm{cm}^{-2}$ (Schutte et al. 1993) and for GCA and GCO whose quantification is impossible. Their column density not being available, their integrated absorbance is displayed instead.

3.3.2.8 $\mathrm{C}_{3}$ COMs. In the case of GCA and GCO, unfortunately, solid phase band strengths are not yet known making their quantification impossible. However their integrated absorbance show that for exp. 1, an important part of GCO and GCA is formed during the heating process which is not the case for two other experiments. Globally, their quantity decreases with the irradiation temperature, maybe because POM over-consumes formaldehyde molecules which therefore are not available to form other complex species.

3.3.2.9 Comparison of EG and GA. EG/GA ratios are 3.4, 4.5 and 0.7 when irradiation temperatures are 15,50 and $90 \mathrm{~K}$ respectively. The first ratio is different from the result obtained in a previous experiment done at $13 \mathrm{~K}$ (Butscher et al. 2016) where the ratio EG/GA was near 1. In Butscher et al. (2016), ices were more diluted $\left(\mathrm{H}_{2} \mathrm{O} / \mathrm{H}_{2} \mathrm{CO}=5 / 1\right.$ compared to $3 / 1$ here $)$ and the irradiation time needed to reach $30 \%$ of formaldehyde photolysis was much higher ( $23 \mathrm{~h}$ compared to $170 \mathrm{~min}$ here). This can explain the observed difference for the EG/GA ratio between both experiments. At $50 \mathrm{~K}$, the EG/GA ratio is maximum indicating that more $\mathrm{CH}_{2} \mathrm{OH}$ is formed compared to $\mathrm{HCO}$. As a great quantity of $\mathrm{H}$-atoms is formed by $\mathrm{H}_{2} \mathrm{O}$ photolysis, it can make the formation reaction of $\mathrm{CH}_{2} \mathrm{OH}$ by reaction (1) faster than the formation reaction of $\mathrm{HCO}$ by reaction (2) at $50 \mathrm{~K}$ compared to $15 \mathrm{~K}$ :

$$
\mathrm{H}_{2} \mathrm{CO}+\mathrm{H} \rightarrow \mathrm{CH}_{2} \mathrm{OH}
$$

$\mathrm{H}_{2} \mathrm{CO}+h v \rightarrow \mathrm{HCO}+\mathrm{H}$

However, at $90 \mathrm{~K}, \mathrm{H}$-atoms mobility is even more increased but we observe an extinction of EG which confirms the tendency for $\mathrm{H}$-atoms to recombine together rather than to participate in hydrogenation reactions. In the case of GA, at $90 \mathrm{~K}$ it is still greatly produced so that the EG/GA ratio falls to 0.7. As we just show that at this temperature, hydrogenation processes are inhibited so that almost no EG and methanol are formed (that is to say, no $\mathrm{CH}_{2} \mathrm{OH}$ produced), it clearly indicates that GA can be formed without any $\mathrm{CH}_{2} \mathrm{OH}$ radical. Another candidate for its formation is formaldehyde and the potential reaction mechanism is discussed later in the "chemical network" section.
3.3.2.10 Comparison of EG and MeOH. Considering EG and methanol formation behaviors when irradiation temperature rises, it may indicate that formaldehyde hydrogenation in the bulk is optimized at $50 \mathrm{~K}$ but that the second $\mathrm{H}$-addition becomes to be inhibited, otherwise we should also observe a methanol formation increase at $50 \mathrm{~K}$ which is clearly not the case. At this temperature of irradiation, species mobility seems to favor EG formation through $\mathrm{CH}_{2} \mathrm{OH}$ compared to over-hydrogenation which would yield methanol. These experiments show also that water molecule is not an efficient donor of $\mathrm{H}$-atoms through $\mathrm{H}$-abstraction processes. If it was the case, methanol quantity would follow EG trend.

Globally, these new results show that irradiation temperature plays an important role in the final ice composition. Branching ratios seem to be greatly affected by irradiation temperature so that some species are more or less produced depending on the ice temperature during photolysis. $\mathrm{H}$-atom behavior is also affected as hydrogenation formed products are inhibited when temperature is too high.

\section{DISCUSSION: CHEMICAL NETWORK}

\subsection{Photodissociation processes}

The first reactions taking place in all experiments are formaldehyde and water dissociations induced by VUV photons. In the case of water, we expect reaction 3 to occur (Ung \& Back 1964):

$\mathrm{H}_{2} \mathrm{O}+h v \rightarrow \mathrm{OH}+\mathrm{H}$

In addition to reaction 3, reaction 4 is a well known photodissociation channel in gas phase (Stief et al. 1975; Slanger \& Black 1982):

$\mathrm{H}_{2} \mathrm{O}+h v \rightarrow \mathrm{O}+\mathrm{H}_{2}$

This channel is only $1 \%$ of the total dissociation process for photon energy lower than $8.5 \mathrm{eV}$ (Stief et al. 1975), but grows up to $10 \%$ at $10.2 \mathrm{eV}$ (Slanger \& Black 1982) in the gas phase. Thus, oxygen atom production in our experiments cannot be excluded. These oxygen atoms may be converted to $\mathrm{CO}_{2}$ through reaction 5 as described in Watanabe et al. (2007): 
$\mathrm{O}+\mathrm{CO} \rightarrow \mathrm{CO}_{2}$

The main route to form $\mathrm{CO}_{2}$ in icy mantles was determined to be reaction 6 (Garrod \& Pauly 2011):

$$
\mathrm{OH}+\mathrm{CO} \rightarrow \mathrm{CO}_{2}+\mathrm{H}
$$

Regarding formaldehyde, its photochemistry in the gas and solid phases has been extensively investigated and two primary photodissociation routes have been shown to be involved (Sodeau \& Lee 1978; Moore \& Weisshaar 1983; Gerakines et al. 1996). The reactions are summarized by the equations 2 and 7 :

$\mathrm{H}_{2} \mathrm{CO}+h v \rightarrow \mathrm{CO}+\mathrm{H}_{2}$

Such elementary reactions are known to be first order processes in the gas phase which implies that its half-life does not depend on the initial quantity. However, the three experiments depicted here were realized with very similar initial conditions ( 3 mbar of $\mathrm{H}_{2} \mathrm{O} / \mathrm{H}_{2} \mathrm{CO}=3 / 1$ ) and a non-negligible temperature effect on photodissociation rate constant is observed as 40,80 and 170 min were needed to photolyse $30 \pm 1 \%$ of formaldehyde at 90,50 and 15 $\mathrm{K}$ respectively. This is explained by the fact that, in solid phase, the rate constant takes into account several physical processes other than pure photo-dissociation cross section, such as recombination and diffusion processes which depend on the system temperature. Thus, at high temperature, photolysed fragments and $\mathrm{H}$-atoms have more translational energy to diffuse, that is to say to move away from each other so that recombination processes are less likely and less time is needed to photo-dissociate the same proportion of sample.

\subsection{Hydrogenation processes}

One of the most interesting effects of temperature on reactivity is the quantity of available $\mathrm{H}$-atoms participating in hydrogenation processes. Table 3 clearly shows that the quantity of methanol -the best example in term of hydrogenation product- decreases when the irradiation temperature increases. Methanol was showed to be efficiently formed from the double hydrogenation of formaldehyde following reaction 8 (Watanabe \& Kouchi 2002; Butscher et al. 2015):

$\mathrm{H}_{2} \mathrm{CO} \stackrel{\mathrm{H}}{\rightarrow} \mathrm{CH}_{2} \mathrm{OH} / \mathrm{CH}_{3} \mathrm{O} \stackrel{\mathrm{H}}{\rightarrow} \mathrm{CH}_{3} \mathrm{OH}$

At $15 \mathrm{~K}$, the quantity of methanol is maximum and it decreases when irradiation temperature is elevated to 50 and $90 \mathrm{~K}$ where its extinction is observed. The elevation of temperature inhibits the formation of the two products of formaldehyde hydrogenation, namely $\mathrm{CH}_{2} \mathrm{OH}$ or $\mathrm{CH}_{3} \mathrm{O}$ radical and methanol while the initial hydrogen budget does not change from an experiment to another. A possible explanation is that at high temperatures, $\mathrm{H}$-atoms can diffuse in the sample that fast they simply recombine to form dihydrogen molecules, which, at these temperatures, desorb easily from the sample.

Alternatively, hydrogen bearing molecules can be used as a reservoir of $\mathrm{H}$-atoms which can be released by $\mathrm{H}$-abstraction process (Chuang et al. 2016). It appears that methanol greatly participates in this type of mechanism as its quantity decreases when samples are heated up from irradiation temperature to $110 \mathrm{~K}$ (Table 3 ). Water molecules may also be a source of $\mathrm{H}$-atoms through $\mathrm{H}$-abstraction processes or during the photolysis but this is difficult to quantify because of its different structure rearrangements with temperature changes. However, H-abstraction processes from water molecules seems to be less efficient than direct hydrogenation with free $\mathrm{H}$ atoms since at $90 \mathrm{~K}$ almost no $\mathrm{MeOH}$ production is observed while $\mathrm{H}$-abstraction reactions dominate.

\subsection{Recombination and addition processes}

\subsubsection{Formation of $\mathrm{C}_{2} \mathrm{COMs}$}

As described in Butscher et al. (2015); Kaiser et al. (2015); Fedoseev et al. (2017), in interstellar ices, GA and EG may form through barrierless recombinations between $\mathrm{HCO}$ and $\mathrm{CH}_{2} \mathrm{OH}$ radicals as shown with reactions (9) and (10):

$\mathrm{HCO}+\mathrm{CH}_{2} \mathrm{OH} \rightarrow \mathrm{CHOCH}_{2} \mathrm{OH}(\mathrm{GA})$

$\mathrm{CH}_{2} \mathrm{OH}+\mathrm{CH}_{2} \mathrm{OH} \rightarrow \mathrm{HOCH}_{2} \mathrm{CH}_{2} \mathrm{OH}(\mathrm{EG})$

This reaction scheme, likely in low temperature experiments, appears to be insufficient to explain the formation patterns of EG and GA in our experiments (table 3). Indeed, reactions 9 and 10 show that at least one $\mathrm{CH}_{2} \mathrm{OH}$ radical is mandatory to form GA and EG. However, results show that hydrogenation products such as methanol and $\mathrm{CH}_{2} \mathrm{OH}$ are inhibited while glycolaldehyde formation is boosted when temperature is increased. It follows that an alternative route for $\mathrm{GA}$ formation without $\mathrm{CH}_{2} \mathrm{OH}$ radical has to exist at high temperature. We propose an addition reaction between formaldehyde and its main photolysis product, the HCO radical (Butscher et al. 2016) as shown in equation (11):

\section{$\mathrm{H}_{2} \mathrm{CO} \stackrel{\mathrm{HCO}}{\longrightarrow} \mathrm{CHOCH}_{2} \mathrm{O} \stackrel{\mathrm{H}}{\rightarrow} \mathrm{CHOCH}_{2} \mathrm{OH}(\mathrm{GA})$}

Regarding EG, there is no direct evidence for another mechanism of formation than the reaction 10 as it still need at least one $\mathrm{CH}_{2} \mathrm{OH}$ radical to be formed; if $\mathrm{CH}_{2} \mathrm{OH}$ is not formed, EG formation is simply inhibited. However, the evidence for the non radical-radical addition mechanism for the formation of GA makes the same mechanism for EG likely to occur (reaction 12):

$\mathrm{H}_{2} \mathrm{CO} \stackrel{\mathrm{CH}_{2} \mathrm{OH}}{\longrightarrow} \mathrm{HOCH}_{2} \mathrm{CH}_{2} \mathrm{O} \stackrel{\mathrm{H}}{\rightarrow} \mathrm{HOCH}_{2} \mathrm{CH}_{2} \mathrm{OH}(\mathrm{EG})$

These two mechanisms may be inefficient at $15 \mathrm{~K}$ but they become interesting in high temperature irradiation conditions because there is more thermal energy, which makes possible radical-non radical reactions to occur. Furthermore, initiation of reactions (11) and (12) have relatively low calculated barriers at B3LYP/dev2-TZVP level of theory of 20 and $8 \mathrm{~kJ} \mathrm{~mol}^{-1}$ respectively (Butscher et al. 2019) which make them very likely to occur in warmer environments. The temperature increase enhances the mobility of radical species and knowing that their reaction with formaldehyde is energetically feasible makes reactions (11) and (12) of main interest. The amount of formaldehyde is much more important than the quantity of radicals (only $30 \%$ is consumed during irradiation) so that reactions (9) and (10) should be insignificant at high temperature of irradiation at least. This statement is also supported by the fact that for exp. 1, a great part of EG and GA is formed during the heating process, where all species gain in mobility and reaction barriers can be easily overcome.

Another interesting result is the formation pattern of EG. It appears that it is optimally produced when irradiation temperature 
is around $50 \mathrm{~K}$ as it represents $27 \%$ of products compared to only 15 and $8 \%$ after irradiation at 15 and $90 \mathrm{~K}$, respectively. The temperature increase surely prevents hydrogenation processes to occur but it may also increase diffusion processes and reaction kinetics. It must exist a temperature where the combination of these two opposite effects gives a maximum quantity of $\mathrm{CH}_{2} \mathrm{OH}$ available in the ice and thus, a maximum quantity of EG formed at the end.

It should be pointed out that no methyl formate (MF) has been detected in our experiments although it is one of the most observed COMs in the ISM (El-Abd et al. 2019). MF is supposed to be formed from the recombination of $\mathrm{CH}_{3} \mathrm{O}$ and $\mathrm{HCO}$ radicals (Bennett \& Kaiser 2007; Chuang et al. 2017) as shown in reaction 13:

\section{$\mathrm{CH}_{3} \mathrm{O}+\mathrm{HCO} \rightarrow \mathrm{CH}_{3} \mathrm{OCHO}$}

Our experiments show that formaldehyde and water are not efficient precursors for the formation of MF as it has never been observed in such experiments (Butscher et al. 2016, 2019). Also, the clear formation of EG in exp. 1 and exp. 2 may be indicative of $\mathrm{CH}_{2} \mathrm{OH}$ radical formation. However the absence of MF signal seems to discredit the formation of $\mathrm{CH}_{3} \mathrm{O}$ radical. $\mathrm{MF}$ would have been a good probe for $\mathrm{CH}_{3} \mathrm{O}$ production (reaction 13) and its nondetection seems to indicate that formaldehyde hydrogenation (reaction 8) preferentially yields $\mathrm{CH}_{2} \mathrm{OH}$ than $\mathrm{CH}_{3} \mathrm{O}$ (Butscher et al. 2016).

\subsubsection{Formation of $\mathrm{C}_{3} \mathrm{COMs}$}

Considering that reactions (11) and (12) are plausible, it means that reactions between a radical species and a carbonyl (at least aldehyde) function is likely to occur as long as enough energy is brought to overcome their low reaction barriers. We can therefore postulate a similar addition mechanism for the GCA and GCO formation as glycolaldehyde possesses an aldehyde function as well. The two reactions involving GA for the elongation of the carbon chain would be (14) and (15):<smiles>O=CCOCC(=O)NC(=O)C(O)COCCNC(=O)C(O)CO</smiles>

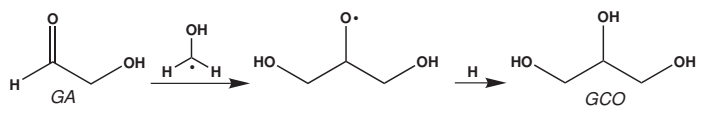

Theoretical calculations seem to disfavor this reaction scheme because for the reaction (14) the calculated reaction barrier at the M06-2X-D3/aug-cc-pVTZ level of theory is more than two times higher than for reaction (11) (34 compared to $14 \mathrm{~kJ} \mathrm{~mol}^{-1}$, see Butscher et al. (2017)). Considering that the probability for a $\mathrm{HCO} / \mathrm{CH}_{2} \mathrm{OH}$ radical to react with a formaldehyde molecule is higher than with glycolaldehyde (which has to be formed), and considering the two times more important barrier for the reaction (14) to occur, it is surprising to have such clear IR and mass results for the GCA/GCO formation. One has to keep in mind that theoretical calculations are done for isolated molecules which is clearly not the case in our experiments. Such calculated values are used to determine which reaction is more likely.

An alternative mechanism leading to GCA and GCO is a polymerization-like reaction not passing through GA but keeping a radical species at each step. Wang \& Bowie (2010) have proposed a very similar mechanism for the formation of sugars from formaldehyde and $\mathrm{CH}_{2} \mathrm{OH}$ radical. In our reaction scheme, one radical (HCO or $\mathrm{CH}_{2} \mathrm{OH}$ ) would react on a formaldehyde molecule (like in reactions (11) and (12)), which is favored thanks to its high quantity in the ice, forming an O-bearing radical which would rearrange into the corresponding C-bearing radical, following reactions (16) and (17):
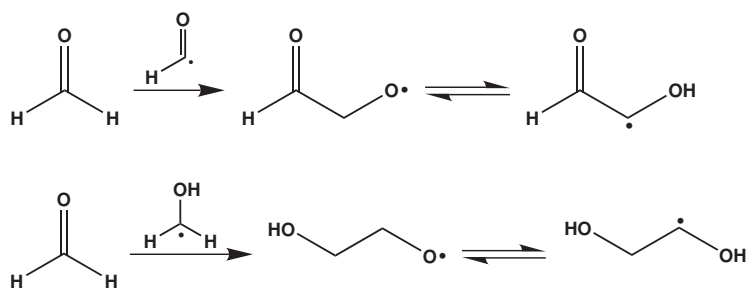

Such an isomerization process via intramolecular hydrogen atom transfer is often forbidden in the gas phase at low temperature. Indeed, activation barrier of such reactions are greater than $100 \mathrm{~kJ}$ $\mathrm{mol}^{-1}$ making them unlikely at low temperature in the gas phase of the ISM (Wang \& Bowie 2010, 2012). For example, the calculated barrier for $\mathrm{HOCH}_{2} \mathrm{CH}_{2} \mathrm{O} / \mathrm{HOCH}_{2} \mathrm{CHOH}$ isomerization (reaction 17) is $117 \mathrm{~kJ} \mathrm{~mol}^{-1}$ resulting in a very low rate at low temperature even if tunneling effects are taken into account (Wang \& Bowie 2012). The same behavior is observed for the $\mathrm{CH}_{3} \mathrm{O} / \mathrm{CH}_{2} \mathrm{OH}$ isomerization where an activation barrier of $125 \mathrm{~kJ} \mathrm{~mol}^{-1}$ has been calculated. However, it has been theoretically reported that small molecules as $\mathrm{H}_{2} \mathrm{O}$ or $\mathrm{HCOOH}$ can facilitate the isomerization of $\mathrm{CH}_{3} \mathrm{O}$ to $\mathrm{CH}_{2} \mathrm{OH}$ via formation of a doubly hydrogen-bonded transition state making the $\mathrm{CH}_{3} \mathrm{O} / \mathrm{CH}_{2} \mathrm{OH}$ isomerization more likely in condensed environments (Buszek et al. 2011; Lee et al. 2015). This is in good agreement with experimental results. Lee et al. (2015) observed a fast $\left(7.6 \times 10^{-3} \mathrm{~s}^{-1}\right) \mathrm{CH}_{3} \mathrm{O}$ conversion into $\mathrm{CH}_{2} \mathrm{OH}$ at $4 \mathrm{~K}$ in parahydrogen. They suspected that $\mathrm{CH}_{3} \mathrm{O}$ reacts readily with $\mathrm{H}_{2}$ to form $\mathrm{CH}_{2} \mathrm{OH}$. Moreover, Iwasaki \& Toriyama (1978) reported ESR spectra arising from $\mathrm{CH}_{3} \mathrm{O}$ trapped in polycrystalline methanol X-ray irradiated at $4.2 \mathrm{~K}$. They observed that $\mathrm{CH}_{3} \mathrm{O}$ is no longer stable and is fully converted into $\mathrm{CH}_{2} \mathrm{OH}$ in a few minutes after annealing at $77 \mathrm{~K}$. Accordingly, we can assume that hydrogen atom transfer leading to $\mathrm{C}$-bearing radical from O-bearing radical as in reaction 16 and 17 are likely to occur at low temperature in icy environments.

At this stage, from the O- or C-bearing radical (reactions 16 and 17), hydrogenation reactions would simply give GA or EG, but depending on the amount of formaldehyde around, the growth of the chain is also possible. From the new C-bearing radical, we can expect again a reaction with a formaldehyde molecule as it is the main containing carbonyl partner. A new O-bearing radical would be obtained, this time with a three carbon chain. This new radical can be easily hydrogenated, yielding GCA or GCO depending on the initiating radical ( $\mathrm{HCO}$ or $\left.\mathrm{CH}_{2} \mathrm{OH}\right)$, giving reactions (18) and (19):

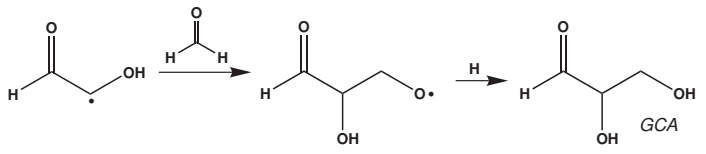

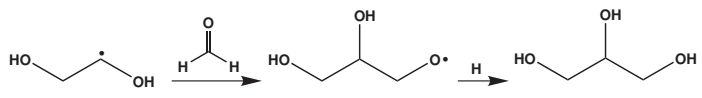


Four- or more-carbon bearing COM formation is not excluded but they are not detected in our experimental conditions.

\subsubsection{Formation of POM}

Polyoxomethylene was showed to be formed at $13 \mathrm{~K}$ in interstellar ice analogues from the VUV photolysis of pure formaldehyde solid films but not when mixed with water (Butscher et al. 2016). In this contribution, we add the possibility to form this molecule in astrochemically relevant ices composed of formaldehyde and water when irradiation temperature is set at 50 or $90 \mathrm{~K}$. The formation of such a molecule takes place in three steps: an initiation step (reaction 20), a propagation step (reaction 21) and a termination step (reaction 22). In Butscher et al. (2016), the two possible initiators were $\mathrm{CH}_{2} \mathrm{OH}$ and $\mathrm{HCO}$ as there was only formaldehyde in yieldingPOM samples. Here, we can add $\mathrm{OH}$ radical as an initiator as there is a great quantity of water in our ices. If $\mathrm{R}$ is one of the three potential initiators $\left(\mathrm{HCO}, \mathrm{CH}_{2} \mathrm{OH}\right.$ and $\left.\mathrm{OH}\right)$, thus reaction 20 is the first step of the reaction:

\section{$\mathrm{R} \cdot+\mathrm{CH}_{2} \mathrm{O} \rightarrow \mathrm{RCH}_{2} \mathrm{O}$}

Then, the product of reaction 20 can react again on $(n)$ other formaldehyde molecules during the propagation step, following reaction 21:

$$
\mathrm{RCH}_{2} \mathrm{O}^{\cdot}+n \mathrm{CH}_{2} \mathrm{O} \rightarrow \mathrm{RCH}_{2} \mathrm{O}\left(\mathrm{CH}_{2} \mathrm{O}\right)_{n-1} \mathrm{CH}_{2} \mathrm{O}^{\cdot}
$$

The final POM molecule is obtained when the polymerization mechanism is stopped by the reaction with another radical species. In our case, it should be an $\mathrm{H}$-atom as there are many available to perform direct $\mathrm{H}$-addition or $\mathrm{H}$-abstraction processes. This is showed in reaction 22:

$$
\mathrm{RCH}_{2} \mathrm{O}\left(\mathrm{CH}_{2} \mathrm{O}\right)_{n-1} \mathrm{CH}_{2} \mathrm{O}+\mathrm{H} \rightarrow \mathrm{RCH}_{2} \mathrm{O}\left(\mathrm{CH}_{2} \mathrm{O}\right)_{n-1} \mathrm{CH}_{2} \mathrm{OH}
$$

The POM chain length may depend on the quantity of $\mathrm{H}$ atoms available as well as of the mobility of the growing chain and formaldehyde molecules. Indeed, the $\mathrm{H}$-atom quantity determines how fast the termination reaction is and the mobility of the different species plays a role on the propagation step kinetic. When irradiation temperature is high, there is a combination of two positive growing effects; there are less $\mathrm{H}$-atoms available to terminate the POM chains and molecules are more mobile as well so that propagation step is faster. In contrast, at low temperature, there is a great quantity of $\mathrm{H}$-atom available and this is the only species diffusing in the ice. As a result, the kinetic rate of the propagation step is slower than the termination reaction one. We observe only shortchain POM when irradiating at $15 \mathrm{~K}$ such as GA or EG which can be viewed as "polymerization products" if the initiation step occurs with $\mathrm{HCO}$ (reaction 16) or $\mathrm{CH}_{2} \mathrm{OH}$ (reaction 17) without propagation step but directly the termination one. Also, the same kind of mechanism can occur with $\mathrm{OH}$ as initiator which would yield methanediol $\left(\mathrm{HOCH}_{2} \mathrm{OH}\right)$, a good candidate for the $\mathrm{m} / \mathrm{z}=47$ fragment $\left(\mathrm{HOCH}_{2} \mathrm{O}\right)$ seen in Fig. 6. This fragment can also be obtained with small three carbon-bearing POM chains initiated by $\mathrm{HCO}$ or $\mathrm{CH}_{2} \mathrm{OH}$ radicals as it can be seen in Butscher et al. (2019). The fact that short- or long-chain POM molecules are formed whether the temperature is low or high is well represented in Fig. 6. The $m / z=47$ fragment is only detected at low temperature (180-210 K) for exp. 1 and begins to be detected at much higher temperatures (240-270 K) for exp. 2 and exp. 3. In the meantime, the relative intensity of the $m / z=47$ fragment for low temperatures is decreasing, showing a less efficient production of short-chain polymers.

\section{ASTROPHYSICAL SIGNIFICANCE}

The experiments presented in this work demonstrate that complex organic molecules and especially sugars, polyols and related compounds are efficiently formed from formaldehyde containing water ice exposed to VUV photons at temperatures ranging from 15 to 90 K (Fig. 8). The molecular abundance of formaldehyde within the icy mantles varies from $1 \%$ to $6 \%$ relative to water in several high and low mass protostars (Dartois 2005; Boogert et al. 2008) or hot corinos (Maret et al. 2004), making formaldehyde a key intermediate in interstellar ices (Schutte et al. 1993; Bossa et al. 2009; Vinogradoff et al. 2011, 2012; Le Roy et al. 2012; Danger et al. 2014; Duvernay et al. 2014). The icy mantles are processed by hydrogenation reactions, high-energy galactic cosmic rays and/or exposed directly to the interstellar UV field. This triggers photo-dissociation of molecules such as water or formaldehyde into reactive radicals. Two distinct carbon-bearing radicals have been shown to be produced by such processes in ice analogue environments which are the formyl and the hydroxymethyl radicals (Bennett \& Kaiser 2007; Hama \& Watanabe 2013; Butscher et al. 2015). These radicals seem to be really important in the formation of the five COMs reported here: glycolaldehyde, ethylene glycol, glyceraldehyde, glycerol and polyxomethylene, and their formation is likely in icy mantles of star forming regions. We demonstrated in a previous paper that GA and EG can be formed in the very early stages of a star forming system as they can be formed at $13 \mathrm{~K}$ under VUV irradiation (Butscher et al. 2016)

This two key molecules are widely detected in the interstellar medium (Hollis et al. 2000, 2001, 2002; Crovisier et al. 2004; Beltrán et al. 2009; Jørgensen et al. 2012; Maury et al. 2014; Coutens et al. 2015) or more recently in comet 67P thanks to the Rosetta mission (Goesmann et al. 2015; Meringer et al. 2018). However, the ratio between these two COMs seems to differ from a region to another. EG/GA is about 5 in NGC 1333 IRAS2A class 0 protostar (Coutens et al. 2015) while is it close to 1 in IRAS 16293-2422 class 0 protostar (Jørgensen et al. 2012) and ranging from 3 to 6 in comets (Crovisier et al. 2004; Biver et al. 2014). The same scheme occurred with our experiments as we obtained ratios ranging from 0.7 to 4.5 depending on the irradiation temperature. These results seem to indicate that the branching ratios for the GA and EG formations are closely related to the temperature. The EG/GA ratio as observed in the gas phase of the ISM could provide additional clues about the physical conditions prior to their formation. Interestingly, the other widely observed COMs methyl formate (MF) and acetic acid (AA) were not observed in our experiments while they represent a large fraction -larger than GA for MF- in star forming regions (El-Abd et al. 2019). It could be explained by the fact that neither formaldehyde nor water are able to generate the key radicals $\left(\mathrm{CH}_{3} \mathrm{O}\right.$ and $\mathrm{CH}_{3}$ ) mandatory for their formation. In the interstellar medium, other molecules such as methanol compose the ices and could be good precursors for the MF and AA formation (Bennett \& Kaiser 2007; El-Abd et al. 2019). The conclusion we can draw from this observation is that formaldehyde seems to be a specific precursor of sugars and related compounds.

Fedoseev et al. (2017) achieved to obtain GCO and GCA from only hydrogenation and barrierless reactions at low temperature (13 $\mathrm{K})$. They used CO/GA ices in order to favour hydrogenation of GA and to artificially increase the quantity of obtained $\mathrm{C}_{3}$ COMs. 


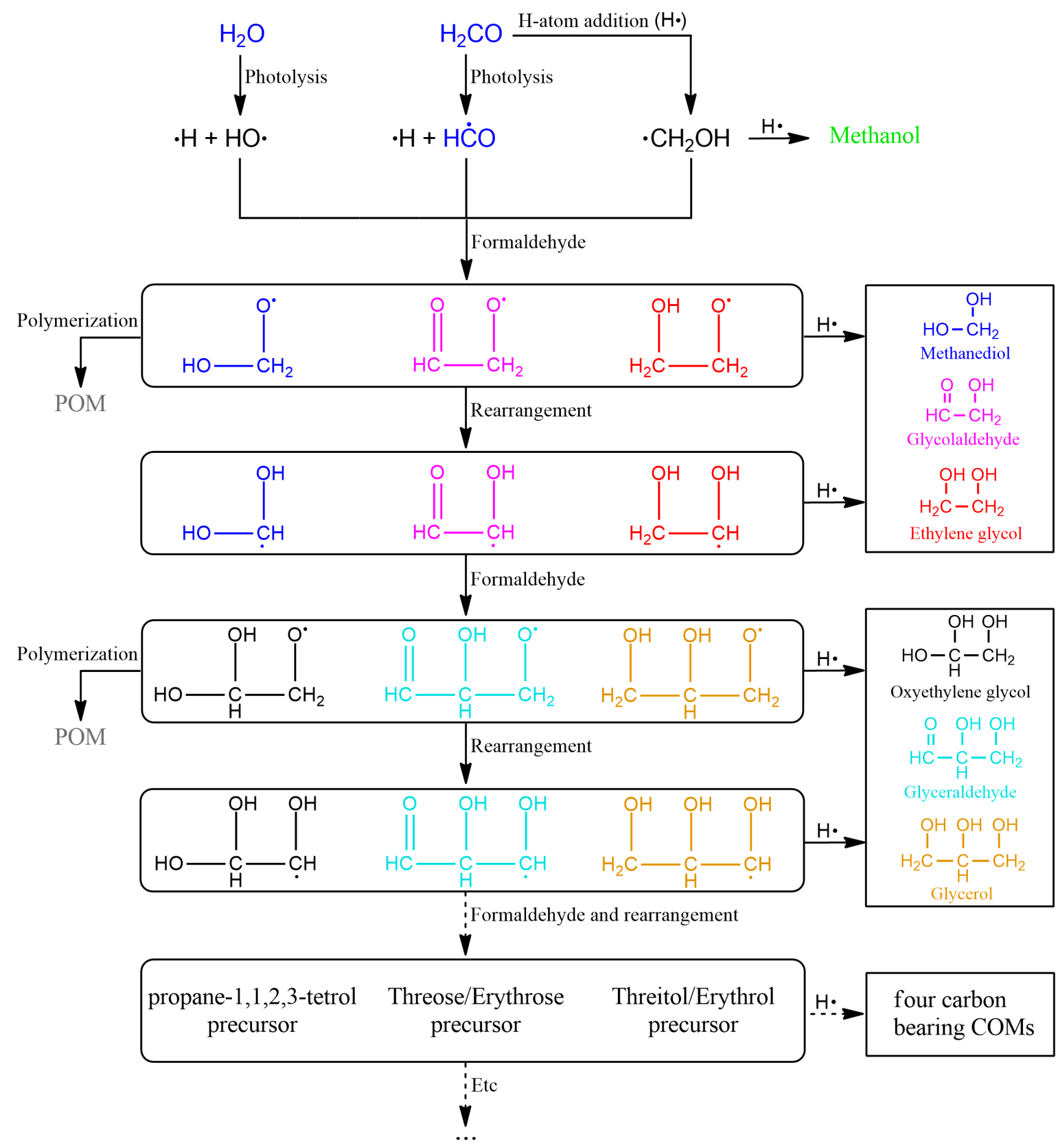

Figure 8. Proposed general formation scheme for polyols and sugars starting from formaldehyde. Molecules with vicinal diols are also displayed as OH radicals could also initiate carbon growth chain reactions. The species in black are not detected in our experiments. The only detected radical is HCO.

It may indicate that GCO and GCA can be formed in molecular clouds. Kaiser et al. (2015) and Zhu et al. (2020) showed that GCO can be formed through energetic processing (energetic electrons) from methanol ices at low temperature. It adds a pathway to the complex scheme of sugar and related compound formation. In this work, a third set of conditions was applied. We used VUV photon irradiation to process astrochemically relevant ices composed of diluted formaldehyde into water. The irradiation temperature was set at 15,50 or $90 \mathrm{~K}$ to simulate the first stages of protostellar evolution (prestellar core to protostar and disk formation) where temperatures can vary from ten to a hundred kelvin (Dunham et al. 2013). This kind of temperatures increases the mobility of species in the ice and open new reaction pathways for low barrier reactions such as radical-non radical reactions. As expected, the resulting ice compositions from our experiments were highly dependent on irradiation temperature. A larger diversity of molecules was found to 
be produced at low temperature of irradiation as hydrogenation and photolysis processes are possible. At high irradiation temperatures, hydrogenation processes begin to be less efficient so that the molecular diversity diminishes. One interesting result is the formation of POM at high irradiation temperatures thanks to the higher mobility of the different species within the ice and a low rate of termination (hydrogenation) reactions. POM is a molecule of high interest in cometary material as is it a reservoir of formaldehyde molecules. It appears that POM could be produced before disk's matter accretion forming comets and asteroids, directly in interstellar ices as formaldehyde polymerization is possible within an icy mantle at temperature below $100 \mathrm{~K}$. Three carbon-bearing COMs were found to be produced in all our experiments such as glyceraldehyde, the first sugar. Kaiser et al. (2015), Zhu et al. (2020) and Fedoseev et al. (2017)'s results combined to ours seem to draw a scheme of how sugars and related compounds could be formed in ice experiments, and by extension, in interstellar and cometary ices. The two key radicals coming from formaldehyde $-\mathrm{CH}_{2} \mathrm{OH}$ and $\mathrm{HCO}$ - have each a specific role in the formation pathways of aldoses ( $\mathrm{HCO}$ initiation, reaction 11) and polyols $\left(\mathrm{CH}_{2} \mathrm{OH}\right.$ initiation, reaction 12). Our work demonstrates that these $\mathrm{C}_{3} \mathrm{COMs}$ can be efficiently and specifically formed from formaldehyde and water under VUV photons (energetic) bombardment conditions as shown in Fig. 8.

Neither GCO nor GCA has already been detected in the ISM but regarding glycerol, it has been in meteorites (Cooper et al. 2001; Cooper \& Rios 2016). This supposes that it is produced in star forming regions or at least in the comets/asteroids themselves. The results presented here together with the results of Fedoseev et al. (2017), Kaiser et al. (2015) and Zhu et al. (2020) indicate that the efficient chemistry which forms GA and EG -two of the most important COMs observed in the ISM- can be extended to larger molecules with an increasing number of carbon atoms.

\section{CONCLUSIONS}

We report new laboratory experiments on the low temperature solid state formation of complex organic molecules -the first sugar glyceraldehyde and its saturated derivative glycerol- through VUV photolysis of astrochemically relevant ices composed of water and formaldehyde. Large differences of product compositions are observed when VUV photolysis is performed at 15,50 or $90 \mathrm{~K}$. When irradiation temperature increases, hydrogenation processes are inhibited while species are more mobile and energy barriers can be overcome. For lower irradiation temperature experiments, hydrogenated products such as methanol and EG dominate the final ices. At higher temperatures of irradiation, these products are inhibited and are replaced by a relatively high production of POM explained by the increased mobility of formaldehyde molecules as well as the low rate of termination reactions. We also proposed -based on experimental and theoretical results- a GA and POM formation mechanism based on radical-non radical reaction via $\mathrm{HCO}$ and formaldehyde. We extended this idea to the other observed COMs (EG, GCA, GCO) drawing a general route for aldose and polyol synthesis in interstellar-like conditions. These COMs can be yielded by polymerization-like mechanisms not passing through GA or EG. We confirm that hydrogenation of formaldehyde preferentially forms $\mathrm{CH}_{2} \mathrm{OH}$ compared to $\mathrm{CH}_{3} \mathrm{O}$ as no methyl formate was detected in our experiments. The results presented here indicate that heavier COMs than GA and EG could exist in star forming regions and during the first steps of protostellar evolution. Future telescope observations may give additional clues on their presence in the ISM as observations are currently limited because of the detection thresholds.

\section{ACKNOWLEDGEMENTS}

The project leading to this publication has received funding from Excellence Initiative of Aix-Marseille University - A*MIDEX, a French "Investissements d'Avenir programme". This work was also supported by the PCMI (Physique et Chimie du Milieu Interstellaire) program and the CNES (Centre National d'Etudes Spatiales). This work was further supported by the ANR SIRC project (Grant ANRSPV202448 2020-2024).

\section{DATA AVAILABILITY}

The data underlying this article will be shared on reasonable request to the corresponding author.

\section{REFERENCES}

Arce H. G., Santiago-García J., Jørgensen J. K., Tafalla M., Bachiller R., 2008, The Astrophysical Journal, 681, L21

Bacmann A., Taquet V., Faure A., Kahane C., Ceccarelli C., 2012, Astronomy and Astrophysics, 541, 1

Belloche A., Müller H. S., Menten K. M., Schilke P., Comito C., 2013, Astronomy and Astrophysics, 559

Beltrán M. T., Codella C., Viti S., Neri R., Cesaroni R., 2009, Astrophysical Journal, 690, 93

Bennett C. J., Kaiser R. I., 2007, The Astrophysical Journal, 661, 899

Biver N., et al., 2014, Astronomy \& Astrophysics, 566, L5

Blake G. A., Sutton E., Masson C., Phillips T., 1987, Astrophysical Journal, 315,621

Boogert A. C. A., et al., 2008, The Astrophysical Journal, 678, 985

Bossa J., Theule P., Duvernay F., Chiavassa T., 2009, The Astrophysical Journal, 707, 1524

Bouilloud M., Fray N., Bénilan Y., Cottin H., Gazeau M.-C., Jolly A., 2015, Monthly Notices of the Royal Astronomical Society, 451, 2145

Buckley P., Giguère P. A., 1967, Canadian Journal of Chemistry, 45, 397

Buszek R. J., Sinha A., Francisco J. S., 2011, Journal of the American Chemical Society, 133, 2013

Butscher T., Duvernay F., Theule P., Danger G., Carissan Y., HagebaumReignier D., Chiavassa T., 2015, Monthly Notices of the Royal Astronomical Society, 453, 1587

Butscher T., Duvernay F., Danger G., Chiavassa T., 2016, Astronomy and Astrophysics, 593, 1

Butscher T., Duvernay F., Rimola A., Segado-Centellas M., Chiavassa T., 2017, Physical Chemistry Chemical Physics, 19, 2857

Butscher T., Duvernay F., Danger G., Torro R., Lucas G., Carissan Y., Hagebaum-Reignier D., Chiavassa T., 2019, Monthly Notices of the Royal Astronomical Society, 486, 1953

Caselli P., Ceccarelli C., 2012, The Astronomy and Astrophysics Review, 20, 56

Cernicharo J., Marcelino N., Roueff E., Gerin M., Jiménez-Escobar A., Muñoz Caro G. M., 2012, Astrophysical Journal Letters, 759, 2010

Chen Y.-J., Chuang K.-J., Caro G. M., Nuevo M., Chu C.-C., Yih T.-S., Ip W.-H., Wu C.-Y., 2013, The Astrophysical Journal, 781, 15

Chiar J. E., Tielens A., Whittet D. C. B., Schutte W. A., Boogert A. C. A., Lutz D., Van Dishoeck E. F., Bernstein M. P., 2000, The Astrophysical Journal, 537, 749

Chuang K.-J., Fedoseev G., Ioppolo S., van Dishoeck E., Linnartz H., 2016, Monthly Notices of the Royal Astronomical Society, 455, 1702

Chuang K.-J., Fedoseev G., Qasim D., Ioppolo S., van Dishoeck E., Linnartz H., 2017, Monthly Notices of the Royal Astronomical Society, 467, 2552 
Codella C., Fontani F., Ceccarelli C., Podio L., Viti S., Bachiller R., Benedettini M., Lefloch B., 2015, Monthly Notices of the Royal Astronomical Society: Letters, 449, L11

Cooper G., Rios A. C., 2016, Proceedings of the National Academy of Sciences, 113, E3322

Cooper G., Kimmich N., Belisle W., Sarinana J., Brabham K., Garrel L., 2001, Nature, 414, 879

Coutens A., Persson M. V., Jørgensen J. K., Wampfler S. F., Lykke J. M., 2015, Astronomy and Astrophysics, 576

Crovisier J., Bockelée-Morvan D., Colom P., Biver N., Despois D., Lis D. C., 2004, Astronomy \& Astrophysics, 418, 1141

Danger G., Rimola A., Mrad N. A., Duvernay F., Roussin G., Theule P., Chiavassa T., 2014, Physical Chemistry Chemical Physics, 16, 3360

Dartois E., 2005, in , ISO Science Legacy. Springer, pp 293-310, doi:10.1007/1-4020-3844-5_13

Dunham M. M., et al., 2013, The Astronomical Journal, 145, 94

Duvernay F., Danger G., Theulé P., Chiavassa T., Rimola A., 2014, The Astrophysical Journal, 791, 75

El-Abd S. J., Brogan C. L., Hunter T. R., Willis E. R., Garrod R. T., McGuire B. A., 2019, The Astrophysical Journal, 883, 129

Fedoseev G., Cuppen H. M., Ioppolo S., Lamberts T., Linnartz H., 2015, Monthly Notices of the Royal Astronomical Society, 448, 1288

Fedoseev G., Chuang K. J., Ioppolo S., Qasim D., van Dishoeck E. F., Linnartz H., 2017, The Astrophysical Journal, 842, 52

Garrod R. T., Pauly T., 2011, The Astrophysical Journal, 735, 15

Gerakines P., Schutte W., Ehrenfreund P., 1996, Astronomy and Astrophysics, 312, 289

Gibb E. L., Whittet D. C. B., Boogert A. C. A., Tielens A. G. G. M., 2004, The Astrophysical Journal Supplement Series, 151, 35

Goesmann F., et al., 2015, Science, 349, aab0689

Guzmán V. V., Pety J., Gratier P., Goicoechea J. R., Gerin M., Roueff E., Le Petit F., Le Bourlot J., 2014, Faraday Discussions, 168, 103

Hama T., Watanabe N., 2013, Chemical Reviews, 113, 8783

Harvey K., Ogilvie J., 1962, Canadian Journal of Chemistry, 40, 85

Hollis J. M., Lovas F. J., Jewell P. R., 2000, The Astrophysical Journal, 540, L107

Hollis J., Vogel S., Snyder L., Jewell P., Lovas F., 2001, The Astrophysical Journal Letters, 554, L81

Hollis J. M., Lovas F. J., Jewell P. R., Coudert L. H., 2002, The Astrophysical Journal, 571, L59

Hudson R., Moore M., 1999, Icarus, 140, 451

Hudson R. L., Moore M. H., Cook A. M., 2005, Advances in Space Research, 36,184

Iwasaki M., Toriyama K., 1978, Journal of the American Chemical Society, 100, 1964

Jiménez-Serra I., et al., 2016, The Astrophysical Journal, 830, L6

Jørgensen J. K., Favre C., Bisschop S. E., Bourke T. L., Van Dishoeck E. F., Schmalzl M., 2012, Astrophysical Journal Letters, 757

Jørgensen J. K., et al., 2016, Astronomy and Astrophysics, 595

Kaiser R. I., Maity S., Jones B. M., 2015, Angewandte Chemie - International Edition, 54, 195

Kerkhof O., Schutte W., Ehrenfreund P., et al., 1999, Astronomy and Astrophysics, 346, 990

Le Roy L., Briani G., Briois C., Cottin H., Fray N., Thirkell L., Poulet G., Hilchenbach M., 2012, Planetary and space science, 65, 83

Lee Y. F., Chou W. T., Johnson B. A., Tabor D. P., Sibert E. L., Lee Y. P., 2015, Journal of Molecular Spectroscopy, 310, 57

Maity S., Kaiser R. I., Jones B. M., 2015, Physical Chemistry Chemical Physics, 17, 3081

Marcelino N., Cernicharo J., Agúndez M., Roueff E., Gerin M., MartínPintado J., Mauersberger R., Thum C., 2007, The Astrophysical Journal Letters, 665, L127

Maret S., et al., 2004, Astronomy \& Astrophysics, 416, 577

Martín-Pintado J., Rizzo J. R., de Vicente P., Rodríguez-Fernández N. J., Fuente A., 2001, The Astrophysical Journal, 548, L65

Maury A. J., et al., 2014, Astronomy \& Astrophysics, 563, L2

McManus J. R., Martono E., Vohs J. M., 2014, Catalysis Today, 237, 157

Meinert C., et al., 2016, Science, 352, 1
Meringer M., Giri C., Cleaves H. J., 2018, ACS Earth and Space Chemistry, 2, 1256

Milligan D. E., Jacox M. E., 1969, The Journal of Chemical Physics, 51, 277

Mispelaer F., et al., 2013, Astronomy and Astrophysics, 555, 1

Moore C. B., Weisshaar J. C., 1983, Annual Review of Physical Chemistry, 34,525

Neill J. L., et al., 2014, Astrophysical Journal, 789

Noble J., Theule P., Mispelaer F., Duvernay F., Danger G., Congiu E., Dulieu F., Chiavassa T., 2012, Astronomy \& Astrophysics, 543, A5

Öberg K. I., Bottinelli S., Jørgensen J. K., Van Dishoeck E. F., 2010, Astrophysical Journal, 716, 825

Paardekooper D. M., Bossa J. B., Linnartz H., 2016, Astronomy and Astrophysics, 592

Requena-Torres M. A., Martin-Pintado J., Martin S., Morris M. R., 2008, The Astrophysical Journal, 672, 352

Rivilla V., Fontani F., Beltrán M., Vasyunin A., Caselli P., Martín-Pintado J., Cesaroni R., 2016, The Astrophysical Journal, 826, 161

Schutte W., Allamandola L., Sandford S., 1993, Icarus, 104, 118

Slanger T. G., Black G., 1982, The Journal of Chemical Physics, 77, 2432

Sodeau J. R., Lee E. K., 1978, Chemical Physics Letters, 57, 71

Stief L. J., Payne W. A., Klemm R. B., 1975, The Journal of Chemical Physics, 62, 4000

Taquet V., López-Sepulcre A., Ceccarelli C., Neri R., Kahane C., Charnley S. B., 2015, Astrophysical Journal, 804, 1

Tercero B., et al., 2015, Astronomy and Astrophysics, 582, 1

Ung A.-M., Back R., 1964, Canadian Journal of Chemistry, 42, 753

Vastel C., Ceccarelli C., Lefloch B., Bachiller R., 2014, Astrophysical Journal Letters, 795, 6

Vinogradoff V., Duvernay F., Danger G., Theulé P., Chiavassa T., 2011, Astronomy \& Astrophysics, 530, A128

Vinogradoff V., Rimola A., Duvernay F., Danger G., Theulé P., Chiavassa T., 2012, Physical Chemistry Chemical Physics, 14, 12309

Wang T., Bowie J. H., 2010, Organic \& biomolecular chemistry, 8, 4757

Wang T., Bowie J. H., 2012, Organic and Biomolecular Chemistry, 10, 3219

Watanabe N., Kouchi A., 2002, The Astrophysical Journal Letters, 571, L173

Watanabe N., Mouri O., Nagaoka A., Chigai T., Kouchi A., Pirronello V., 2007, The Astrophysical Journal, 668, 1001

Zhu C., Turner A. M., Meinert C., Kaiser R. I., 2020, The Astrophysical Journal, 889, 134

Zweckmair T., Böhmdorfer S., Bogolitsyna A., Rosenau T., Potthast A., Novalin S., 2014, Journal of chromatographic science, 52, 169 


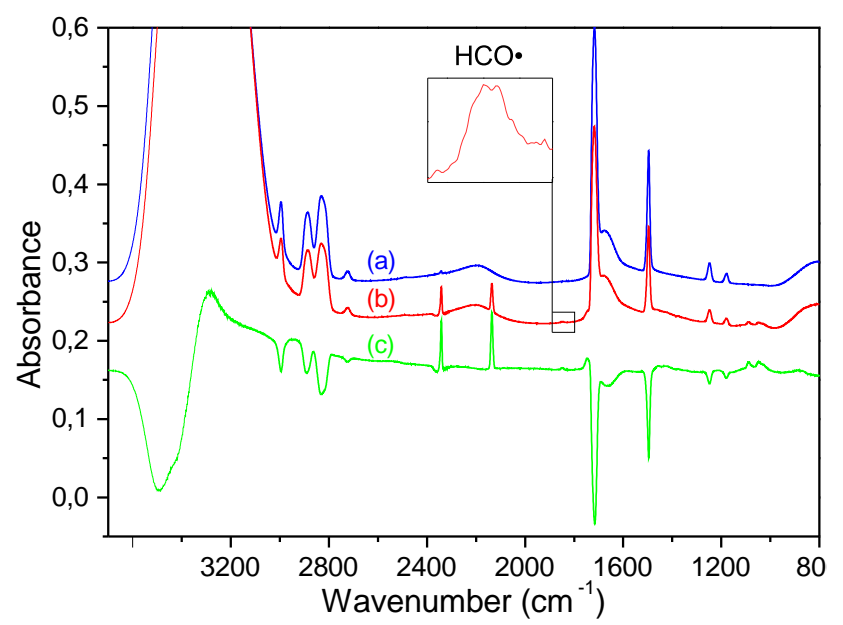

Figure A1. Infrared spectra of an $\mathrm{H}_{2} \mathrm{O} / \mathrm{H}_{2} \mathrm{CO}=3 / 1$ ice at $50 \mathrm{~K}$ before irradiation (a), after $80 \mathrm{~min}$ of VUV photolysis (b) and difference specrum $((c)=(b)-(a))$. Green spectrum has been multiplied by a factor of two.

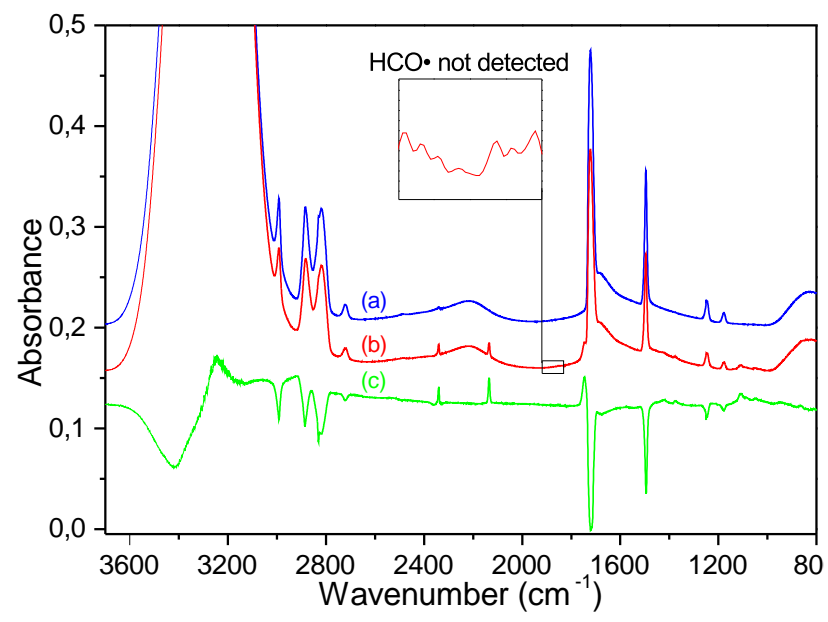

Figure A2. Infrared spectra of an $\mathrm{H}_{2} \mathrm{O} / \mathrm{H}_{2} \mathrm{CO}=3 / 1$ ice at $90 \mathrm{~K}$ before irradiation (a), after $40 \mathrm{~min}$ of VUV photolysis (b) and difference specrum $((c)=(b)-(a))$. Green spectrum has been multiplied by a factor of two.

This paper has been typeset from a $\mathrm{T}_{\mathrm{E}} \mathrm{X} / \mathrm{L} \mathrm{A} \mathrm{T}_{\mathrm{E}} \mathrm{X}$ file prepared by the author. 


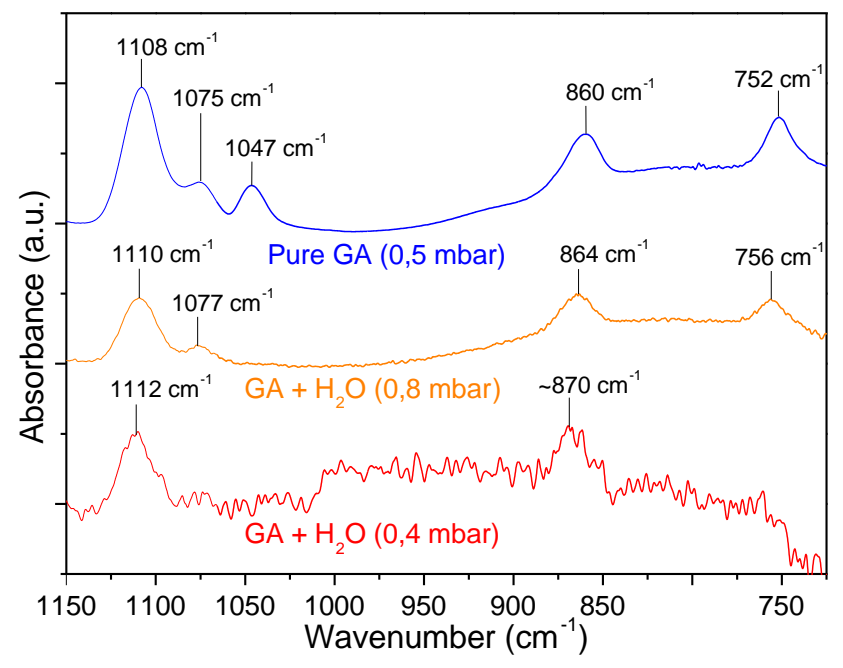

Figure A3. Influence of environment in band intensities and positions for 0.5 mbar of pure GA (blue), 0.8 mbar of a $\mathrm{H}_{2} \mathrm{O} / \mathrm{GA}=24 / 1$ ice (orange) and 0.4 mbar of $\mathrm{a} \mathrm{H}_{2} \mathrm{O} / \mathrm{GA}=10 / 1$ ice (red).

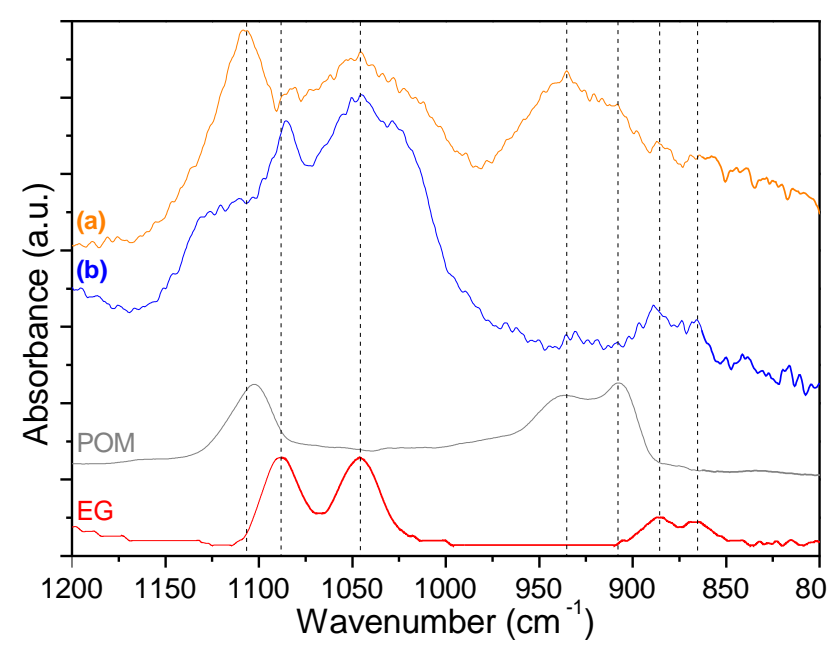

Figure A4. (a) and (b) are $160 \mathrm{~K}$ experimental spectra (after water desorption) of $\mathrm{H}_{2} \mathrm{O} / \mathrm{H}_{2} \mathrm{CO}=3 / 1$ ices irradiated at 90 and $50 \mathrm{~K}$ respectively. POM is clearly detected in (a) and is at the edge of detection in (b). EG is also displayed as the signal around $875 \mathrm{~cm}^{-1}$ in (b) belongs to it. 


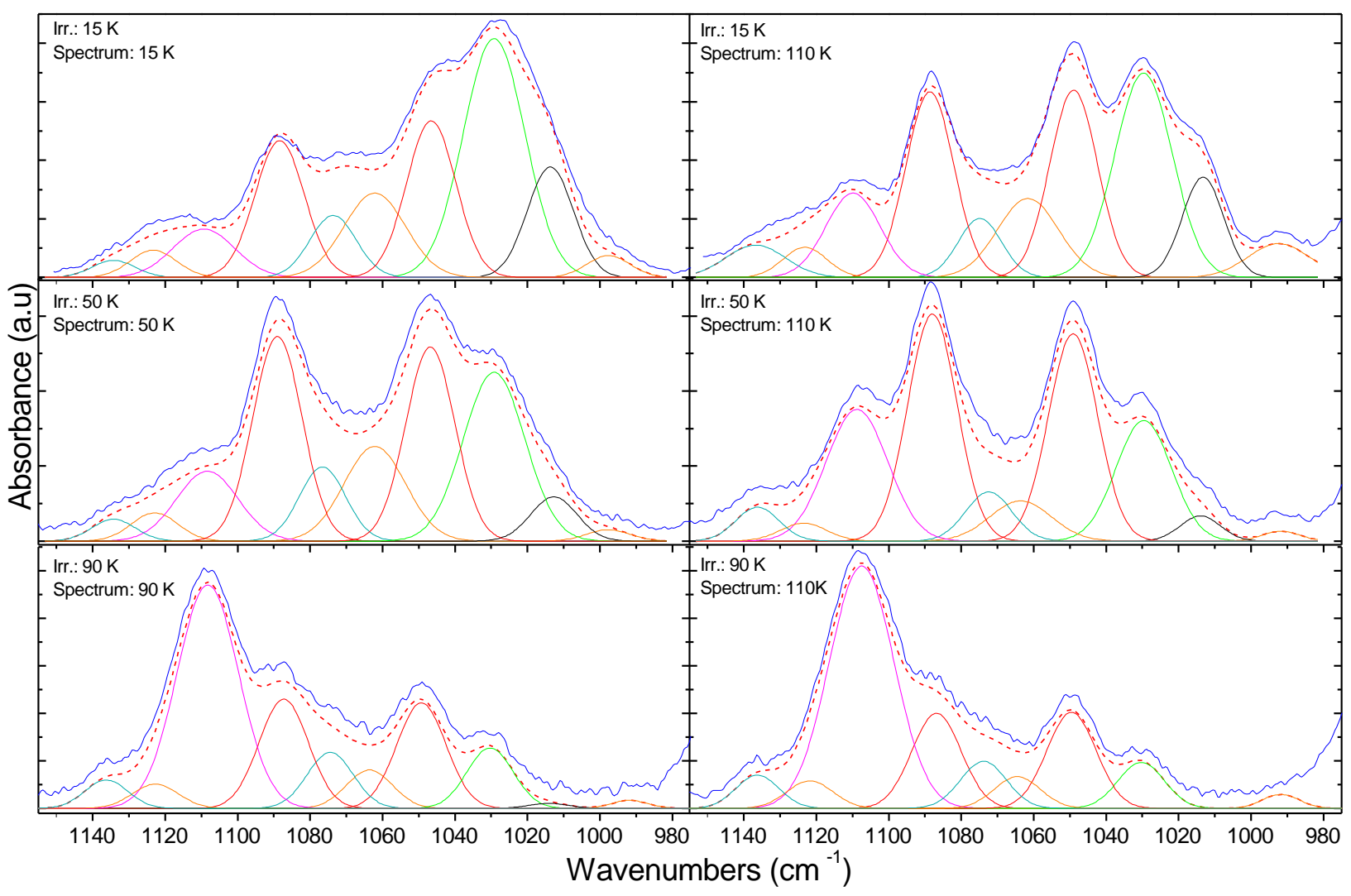

Figure A5. Gaussian fitting in the COM region for all experiments at the irradiation temperature and at $110 \mathrm{~K}$. Blue curves are experimental spectra and dashed red ones are fits. All Gaussian curves have a specific color: for MeOH (green), EG (red), GCA (cyan), GCO (orange). The purple curve belongs to GA and POM when formed as these two species have nearly the same contribution peak around $1110 \mathrm{~cm}^{-1}$. The black Gaussian curve belongs to a species which is not yet attributed. 


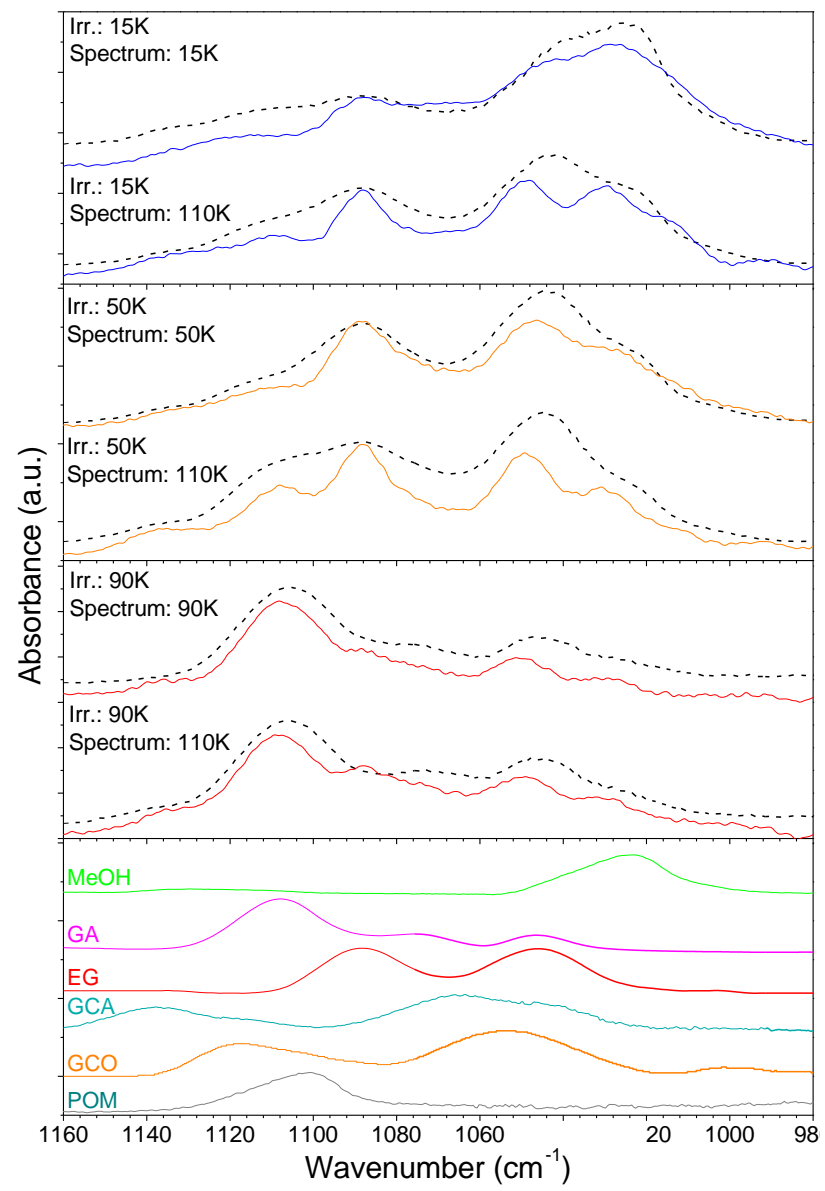

Figure A6. Manual fitting in the COM region for all experiments at the irradiation temperature and at $110 \mathrm{~K}$. Blue curves are experimental spectra and dashed black ones are fits. Reference spectra of $\mathrm{MeOH}$ (green), $\mathrm{GA}$ (purple), EG (red), GCA (cyan), GCO (orange) and POM (grey) are displayed in the lower panel.
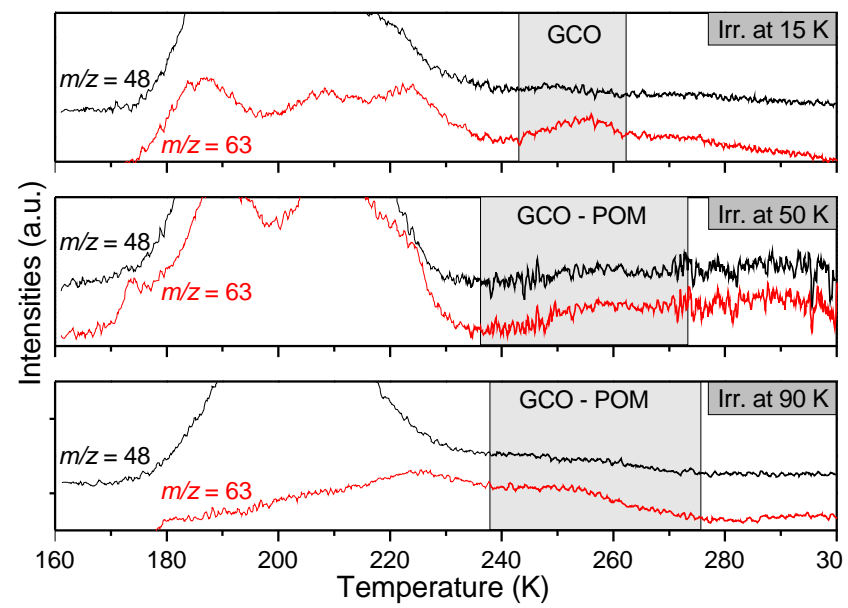

Figure A7. TPD traces $\left(2 \mathrm{~K} \mathrm{~min}^{-1}\right)$ of the 15,50 and $90 \mathrm{~K}$ VUV irradiated $\mathrm{H}_{2} \mathrm{O} / \mathrm{H}_{2}^{13} \mathrm{CO}=3 / 1$ ices. Fragments of $m / z=48$ and 63 are displayed which correspond to the $m / z=47$ and 61 fragments for the ${ }^{12} \mathrm{C}$ experiments respectively.

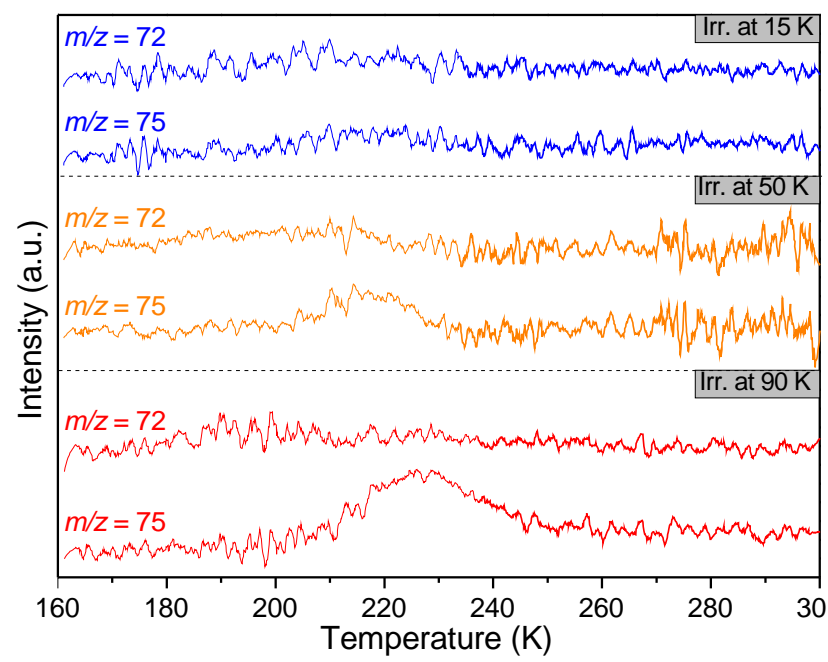

Figure A8. TPD traces $\left(2 \mathrm{~K} \mathrm{~min}^{-1}\right)$ of the 15,50 and $90 \mathrm{~K}$ VUV irradiated $\mathrm{H}_{2} \mathrm{O} / \mathrm{H}_{2}^{13} \mathrm{CO}=3 / 1$ ices. Fragments of $m / z=75$ are compared to the 72 ones.

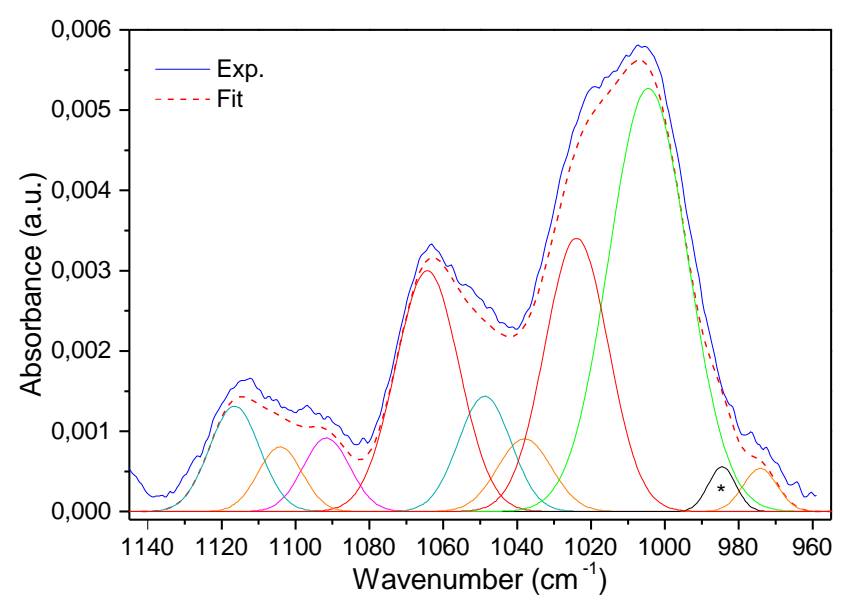

Figure A9. Infrared spectrum of a $15 \mathrm{~K}$ VUV irradiated $\mathrm{H}_{2} \mathrm{O} / \mathrm{H}_{2}^{13} \mathrm{CO}=3 / 1$ ice at $15 \mathrm{~K}$ (solid blue curve) compared to a deconvoluted infrared spectrum (dashed red curve) composed of 10 Gaussians. All Gaussian curves have a specific color: $\mathrm{MeOH}$ (green), GA (purple), EG (red), GCA (cyan), GCO (orange). The black one labeled with a star is not yet attributed. As we do not have any reference spectra in ${ }^{13} \mathrm{C}$, we simply propose the same wavenumber order as in Fig. 3 and $\mathrm{A} 5$ for the different species. All ${ }^{13} \mathrm{C}$ band positions are coherent with ${ }^{12} \mathrm{C}$ experiments as shifts are about $20 \mathrm{~cm}^{-1}$. However, what we propose to be the left band of GCA seems to be too large compared to the GA one, supposing that all band intensity ratios are the same between ${ }^{13} \mathrm{C}$ and ${ }^{12} \mathrm{C}$ experiments. 